\title{
Review Article \\ Obesity and Cancer Progression: Is There a Role of Fatty Acid Metabolism?
}

\author{
Seher Balaban,, ${ }^{1,2}$ Lisa S. Lee, ${ }^{1,2}$ Mark Schreuder, ${ }^{1}$ and Andrew J. Hoy ${ }^{1,2,3}$ \\ ${ }^{1}$ Discipline of Physiology, School of Medical Sciences and Bosch Institute, The University of Sydney, Sydney, NSW 2006, Australia \\ ${ }^{2}$ Charles Perkins Centre, The University of Sydney, Sydney, NSW 2006, Australia \\ ${ }^{3}$ Boden Institute of Obesity, Nutrition, Exercise \& Eating Disorders, The University of Sydney, Sydney, NSW 2006, Australia
}

Correspondence should be addressed to Andrew J. Hoy; andrew.hoy@sydney.edu.au

Received 30 July 2014; Accepted 24 November 2014

Academic Editor: James McManaman

Copyright (C) 2015 Seher Balaban et al. This is an open access article distributed under the Creative Commons Attribution License, which permits unrestricted use, distribution, and reproduction in any medium, provided the original work is properly cited.

\begin{abstract}
Currently, there is renewed interest in elucidating the metabolic characteristics of cancer and how these characteristics may be exploited as therapeutic targets. Much attention has centered on glucose, glutamine and de novo lipogenesis, yet the metabolism of fatty acids that arise from extracellular, as well as intracellular, stores as triacylglycerol has received much less attention. This review focuses on the key pathways of fatty acid metabolism, including uptake, esterification, lipolysis, and mitochondrial oxidation, and how the regulators of these pathways are altered in cancer. Additionally, we discuss the potential link that fatty acid metabolism may serve between obesity and changes in cancer progression.
\end{abstract}

\section{Introduction}

Obesity has long been known to be associated with the development of type 2 diabetes and cardiovascular disease [1]. More recently there is a growing acceptance for a link between obesity and cancer [2]. However, the nature of this relationship remains to be fully elucidated. On one hand obesity increases the risk of many types of cancer, including esophageal, endometrial, thyroid, colon, renal, liver, and breast $[3,4]$. The other aspect is that obesity is also associated with changes in the progression of many cancers. These include higher grade disease in prostate and breast cancer $[5,6]$ and poorer outcomes in endometrial, kidney, pancreas, esophageal, and thyroid cancers [7-9].

Obesity is defined by increased adipose mass arising from energy imbalance. The predominant cell type in adipose tissue is the adipocyte, which is the professional lipid storage cell. Alongside the adipocyte there are a number of other cell types in adipose including preadipocytes, endothelial cells, and immune cells such as resident macrophages. This collective results in a highly complex organ that is central to energy homeostasis and its biology is dramatically altered in obesity. These changes include altered adipocyte biology, such as increased efflux of fatty acids and modified adipokine profile, which is often accompanied by low-grade inflammation and hyperinsulinemia [10]. Whilst these changes are common, they are not defining characteristics of the entire obese population. For example, a significant subpopulation is metabolically healthy, retains insulin sensitivity, and has normal lipid and inflammation profiles [11]. Likewise, there are other populations, including the "metabolically obese, normal weight" $[12,13]$ and those with familial lipodystrophy $[14,15]$ that have pathogenic metabolic profiles. These other populations highlight that inflammatory mediators and increased growth factor availability (e.g., IGF-1, insulin; see [16]) are not the only mechanisms linking obesity with cancer. In this review, we will highlight the evidence that exists on the role that fatty acid metabolism plays in cancer biology (Table 1), focusing on pathways of fatty acid uptake, storage, mobilization, and oxidation (Figure 1). This focus is based upon the potential link that fatty acid metabolism may play in the obesity/cancer relationship as excessive lipid accumulation, particularly in abdominal regions, is a definitive characteristic of obesity. 


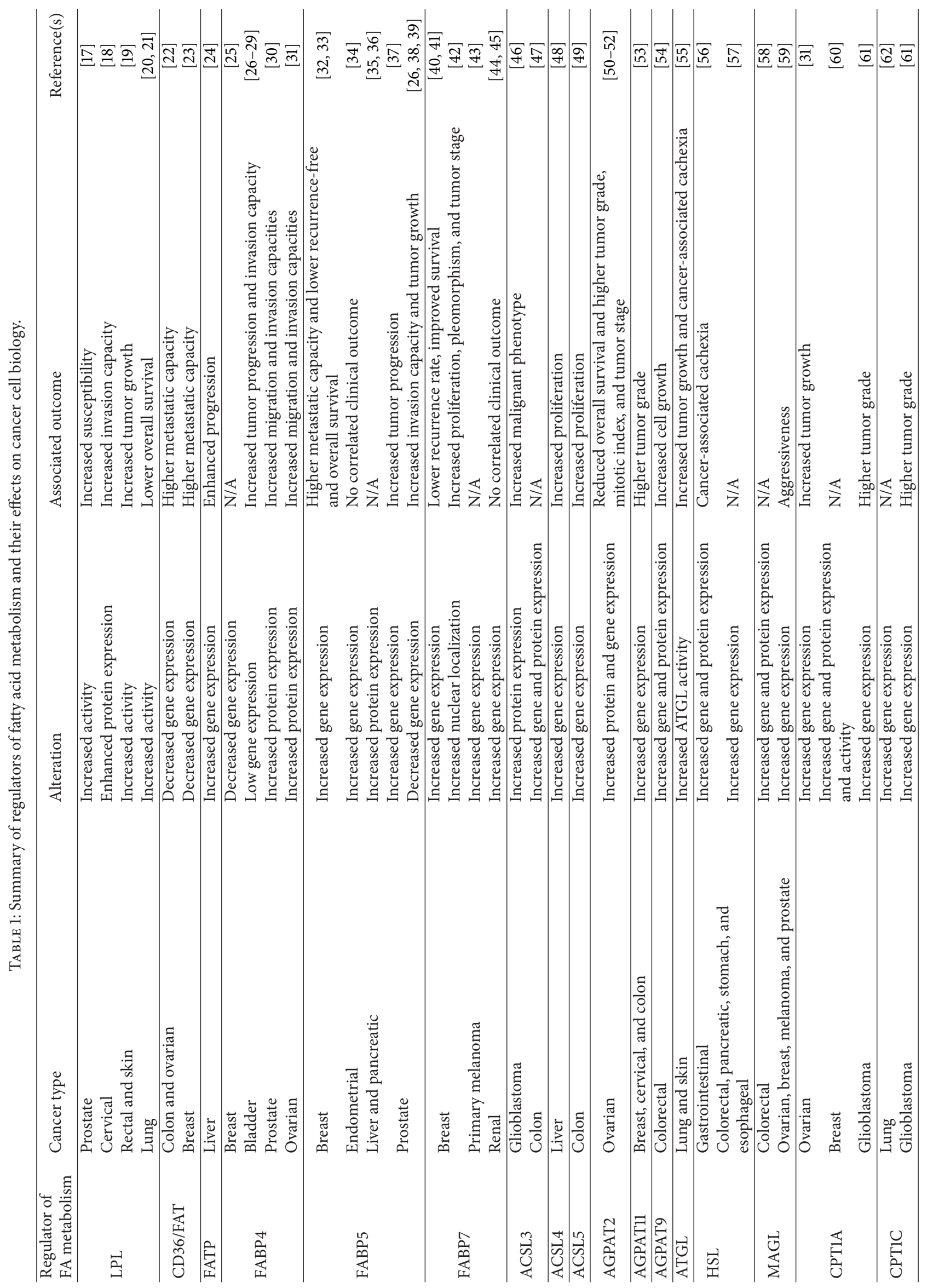




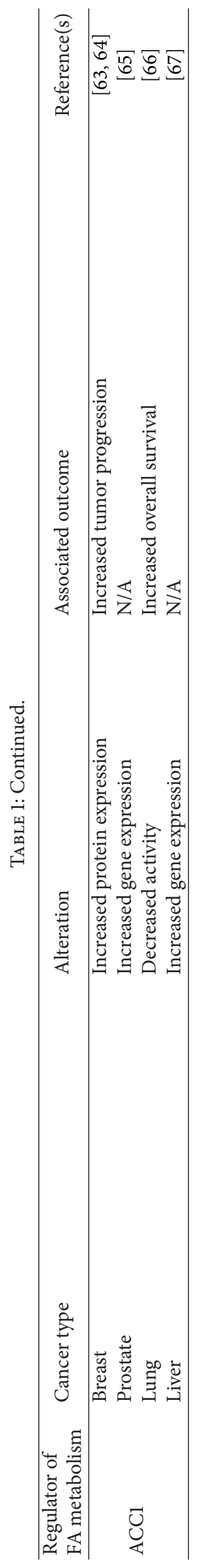




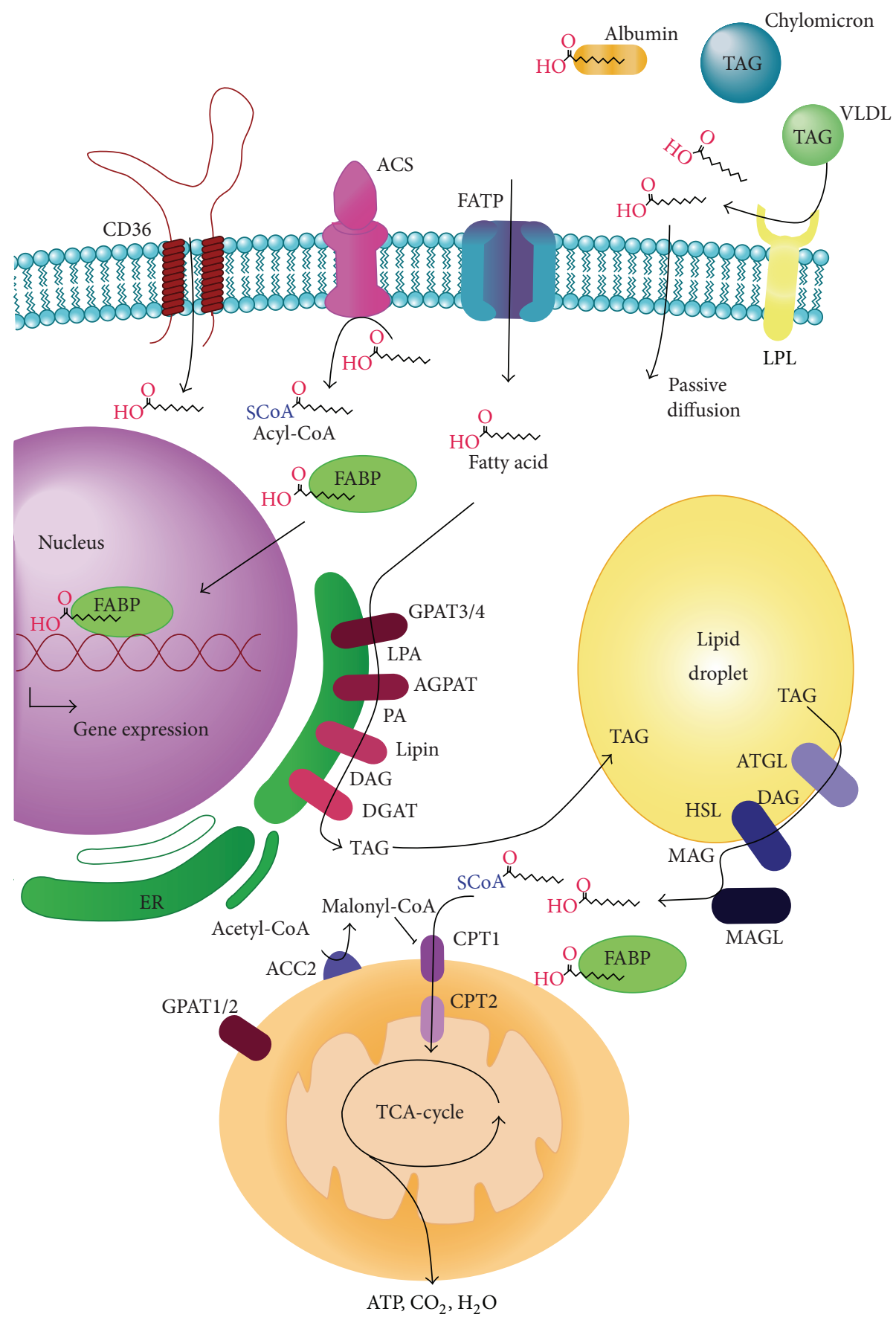

Figure 1: Intracellular fatty acid metabolism. A simplified cartoon of fatty acid metabolism pathways. Fatty acids are transported in the circulation as triacylglycerol (TAG) in lipoproteins and hydrolyzed by lipoprotein lipase (LPL) or they are bound to albumin and are transported across the plasma membrane. A CoA is ligated to fatty acid (FA), and the fatty acyl-CoA (FA-CoA) can enter the glycerolipid synthesis pathway for storage or the mitochondria for oxidation. ACS, acyl-CoA synthase; AGPAT, acyl-CoA: acylglycerol-3-phosphate acyltransferase; ATGL, adipose triglyceride lipase; DAG, diacylglycerol; DGAT, diacylglycerol acyltransferase; GPAT, glycerol-3-phosphate acyltransferase; HSL, hormone-sensitive lipase; LPA, lysophosphatidic acid; MAG, monoacylglycerol; MAGL, monoacylglycerol lipase; PA, phosphatidic acid.

\section{Lipoprotein Hydrolysis, Fatty Acid Transport, and Trafficking}

Long-chain fatty acids travel in the circulation either as free fatty acids that are released from adipocytes bound to albumin or as triacylglycerol (TAG) contained in very lowdensity lipoproteins and chylomicrons. This circulating TAG is hydrolyzed by lipoprotein lipase (LPL) to free fatty acids [68] and then taken up into cells (Figure 1). There remains some controversy as to whether these fatty acids enter the cell 
by passive diffusion or by protein mediated transport. As will be discussed below, it is clear that the latter process does contribute to fatty acid uptake.

2.1. Lipoprotein Hydrolysis. Altered expression of LPL has been reported in many cancers. For example, Narita and colleagues [17] reported a significant association between increased hydrolytic activity of LPL due to the LPL polymorphism (Ser447stop) and the susceptibility to prostate cancer. This association was even stronger in patients with high grade tumors or metastasis. Similarly, this pattern was observed in cervical cancer where LPL is frequently overexpressed in cervical squamous cell carcinomas and associated with an increased invasion capacity [18]. LPL activity has been reported in gastric and rectal cancers, malignant fibrous histiocytomas, and osteosarcomas, with the high proliferating outer area of rectal tumors and fibrous histiocytomas having an enhanced expression of LPL compared with the center [19]. Interestingly, the increased LPL activity in cancer tissue, compared with healthy lung tissue, predicts lower overall survival in non-small-cell lung cancer $[20,21]$. The location of tumor LPL is somewhat controversial as a recent study observed that increased LPL expression was in a subgroup of macrophages and not in cancer cells [69]. These studies mostly report gene expression and therefore future studies linking functional changes in cancer cell LPL activity driving FA release from circulating TAG are required, especially as LPL activity is regulated by a variety of physiological stimuli (see review [70]).

2.2. Fatty Acid Transport. Several proteins have been identified to facilitate the uptake of fatty acids into cells. These include CD36/fatty acid translocase, the fatty acid binding protein (FABP) family, and the fatty acid transport proteins (FATP) [71]. Many of these transporters are ubiquitously expressed, while some display tissue-specific expression [72, 73]. Interestingly, most tissues have coexpression of different fatty acid transporters [74]. The reason for this remains unknown. Possibilities may include differences in uptake capacity and substrate specificity, sensitivity to hormonal stimuli such as insulin [75], or preferences in partitioning into downstream pathway, for example, fatty acid esterification (storage) or oxidation [74].

2.2.1. CD36/Fatty Acid Translocase. CD36, also known as fatty acid translocase (FAT), is a multifunctional transmembrane glycoprotein which is abundantly expressed in cell types active in fatty acid metabolism, including adipocytes, skeletal muscles cells, cardiomyocytes, intestinal enterocytes, monocytes, and hepatocytes [76]. It was originally isolated from platelet membranes as a thrombospondin receptor [77] but has also been shown as a receptor for collagen [78], oxidized lipoproteins [79], and, of greatest interest to this review, long-chain fatty acids [80].

CD36 has been implicated in contributing to cancer progression. Low CD36 gene expression correlates with a higher metastasis grade in colon and ovarian cancers and with low recurrence-free survival [22]. Conversely, CD36 mRNA expression in breast cancer is inversely correlated with the metastatic potential of five breast cancer cell lines [23], where its expression is relatively higher in less aggressive cell lines (T47-D and MCF-7) and almost absent in highly aggressive lines (ZR-75 and MDA-MB-231). This inconsistency between cancer types may be explained by the multifunctionality of CD36. While it functions as a fatty acid transporter, CD36 is also involved in collagen adhesion and, therefore, less CD36 may reduce cell adhesion, providing cancer cells with a higher metastatic potential. That said, the above studies have reported gene or protein expression and not the rates of fatty acid uptake.

Fatty acid transporter abundance is not the only factor regulating FA uptake. An aspect that is often overlooked is that FA uptake is increased by insulin stimulation [81, 82]. This is thought to be mediated by translocation of CD36 to the plasma membrane which has been observed in hepatocytes of obese Zucker rats [83], skeletal muscle [84, 85], cardiomyocytes [86, 87], and ovary cells [85]. This is analogous to the translocation of the insulin sensitive glucose transporter GLUT4 [88, 89].

So far, no studies have investigated the influence of obesity on fatty acid transporters in cancer cells. It is clear from studies in other model systems that CD36 expression and fatty acid uptake are influenced by the microenvironment. For example, CD36 gene expression and protein levels are increased in steatotic hepatocytes [90] and liver biopsies of obese patients, correlating with the circulating free fatty acids levels [91]. In subcutaneous adipose tissue, CD36 protein expression is upregulated in both obese patients and type 2 diabetics [92]. Furthermore, CD36 mRNA expression levels are greatly enhanced in liver and adipose tissue of $o b / o b$ mice, a monogenic model of obesity [93]. Interestingly, incubation of human skeletal muscle cells with adipocyte conditioned media increased both fatty acid uptake and CD36 protein levels [94]. Similar changes in CD36 expression by adipocyte factors, such as adipokines and fatty acids, have been reported in vascular smooth muscle cells [95], cardiomyocytes [86, 96], and adipocytes [97, 98]. Collectively this suggests that changes in adipocyte biology, especially in the context of obesity, can alter CD36 expression in nonadipose cells such as cancer cells that may influence the inherent role that CD36 plays in cancer biology.

2.2.2. Fatty Acid Transport Protein. Fatty acid transport proteins form a highly conserved family of six transporters named FATP1-6 [99]. FATPs are integral membrane proteins and are differentially expressed in a wide variety of cells [100]. These transporters are unique as they can express fatty acyl-CoA synthetase activity [101] as well as an endoplasmic reticulum localization signal domain, at least for FATP4 [102]. Alongside CD36, FATPs regulate long-chain fatty acid and very long-chain fatty acid uptake [103] although the functional differences between CD36 and FATPs are yet to be resolved. A recent study in Madin-Darby Canine cells reported that CD36 is 30-fold more effective in fatty acid uptake compared with FATP4 or the acyl-CoA synthetase ACSL1 [104]. However, cooverexpression of CD36 with either FATP4 or ACSL1 results in an enhanced fatty acid uptake rate greater than expected from the combined individual capacity 
suggesting a synergistic relationship between CD36, FATP4, and ACSL1 to facilitate fatty acid uptake.

To date, only one study has described a possible role for FATPs in tumor metabolism. In this study, FATP mRNA expression is increased in rat hepatomas compared with normal liver tissue which correlated with fatty acid uptake rates [24]. Similar to CD36, FATP expression is influenced by the microenvironment, especially in obesity. FATP expression is elevated in adipose tissue of obese patients $[105,106]$ and in heart [107], skeletal muscle [108], and adipose tissue [109] of rodent models of obesity. Overall, FATPs are important players in lipid uptake and metabolism. However, their role in cancer, especially in the context of obesity-sensitive cancers, is far from understood and further research is needed to elucidate this role.

2.3. Intracellular Trafficking. Fatty acid binding proteins (FABPs) are a family of transport proteins with high affinity for long-chain fatty acids, bile acids, and retinoids [110]. Twelve FABP isoforms have been identified, each with its own tissue and substrate specificity [111]. Although their physiological functions are not fully understood, they appear to facilitate the transport of fatty acids intracellularly and thereby regulate substrate availability for complex lipid synthesis (esterification) and oxidation [112, 113]. Changes in FABP expression have been associated with various diseases including several forms of cancer [113] with FABP5 being the most well characterized FABP isoform in cancer cell biology. For example, prostate [32], endometrial [34], liver [35], pancreatic [36], and breast [32] cancers have increased FABP5 gene or protein expression. However, the observations in prostate are controversial as other studies report reduced expression in multiple prostate cancer lines [26, 38]. Despite this, increased expression of FABP5 in prostate cancer cells increased fatty acid uptake and peroxisome proliferator-activated receptor gamma (PPAR $\gamma)$ expression which enhanced tumor progression [37]. Additionally, overexpression of FABP5 in the benign breast cancer cell line, Rama 37, increased metastatic capacity in rats [32]. Interestingly, expression is higher in estrogen and progesterone negative breast cancer cells, with the highest expression found in triple-negative breast cancer [33]. Furthermore, patients with higher FABP5 mRNA levels had lower recurrence-free and overall survival probabilities [33]. Conversely, invasion capacity and tumor growth were significantly reduced in prostate cancer cells with reduced FABP5 expression [39].

FABP7 has emerged as another participant of intracellular FA metabolism that may contribute to cancer cell biology. Its gene expression is elevated in triple-negative breast cancer cells [40], primary melanomas [43], and renal cell carcinomas $[44,45]$. Interestingly and in contrast to FABP5, FABP7 positive basal-like breast tumors had a significant lower recurrence rate and improved survival rate [41]. In cell culture studies, siRNA knockdown of FABP7 reduced proliferation and invasion in melanoma cells whilst the contraobservation was reported with overexpression enhancing proliferation and invasion [114]. Furthermore, investigations of the organelle-specific roles of FABP7 demonstrated that increased nuclear, but not cytoplasmic, FABP7 is associated with increased proliferation, pleomorphism, and tumor stage in breast cancer suggesting that nuclear FABP7 drives a more aggressive phenotype [42]. However, the mechanism by which FABP7 influences gene expression is yet to be resolved. FABPs may act as coactivators for transcription factors like PPARs [115] or simply function as transporters to carry FA into the nucleus to modulate gene expression [116] via the many intranuclear targets including sterol regulatory binding protein, PPARs, and liver X receptors [117].

FABP 4 has also been implicated in cancer biology. FABP 4 mRNA levels are downregulated in breast cancer cells [25]. Conversely, FABP4 expression is inversely correlated with tumor progression and invasiveness in bladder cancer [2629]. FAPB4 is also susceptible to the extracellular milieu as there is growing evidence that adipocytes increase FABP4 mRNA and protein expression in cancer cells. An elegant study in ovarian cancer demonstrated that coculture with adipocytes increases FABP 4 protein expression and promotes migration and invasion of ovarian cancer cells, while FABP4 deficiency ameliorated the adipocyte-derived metastatic potential [31]. A similar observation of adipocyteinduced increase in FABP4 expression has been reported in PC3 prostate cancer cells [30]. The same study also reported an increased expression of FABP 4 in prostate cancer bone metastasis from high-fat diet mice and prostate cancer patients [30]. The fact that bone marrow is adipocyte-rich [118] suggests a role for adipocytes in enhancing FABP4 expression and thereby playing an important role in cancer progression. Overall, FABPs are emerging as important factors in cancer cell lipid metabolism but more research is needed to fully elucidate the roles of FABPs in healthy tissue and tumor cells and how these are altered by obesity.

\section{Fatty Acid Activation, Esterification, and Mobilization}

Once FAs are taken up by cells, they are activated by the addition of coenzyme A (CoA) to the fatty acid molecule by the actions of long-chain acyl-CoA synthetase (ACSL). From here, evidence suggests that fatty acyl-CoAs can be partitioned into the esterification pathway in the endoplasmic reticulum or the mitochondria for oxidation [119]. Recently, this notion has been challenged by studies in human skeletal muscle [120] and isolated hepatocytes from mice lacking adipose triglyceride lipase (ATGL) [121]. These studies suggest that extracellular FAs enter the esterification pathway to be stored in lipid droplets prior to mitochondrial oxidation. Irrespective of the precise pathways, fatty acids have a multitude of intracellular fates, but at the most basic level FAs can be either oxidized or stored as complex lipids.

3.1. Fatty Acid Activation. ACSLs are a family of enzymes that catalyze the addition of a CoA to a free fatty acid and differ in their preference to the chain length of their fatty acids substrates (short, medium, long, and very long). ACSL1, ACSL3, ACSL4, ACSL5, and ACSL6 are members of the long-chain family that vary in both subcellular localization and substrate specificity [122]. Along with FABPs, individual 
ACSL isoforms have been proposed to channel fatty acids to specific metabolic pathways.

Significant evidence suggests an important role for ACSLs in cancer biology including increased expression of ACSLs in many types of cancer such as colon, liver, lung, brain, and colorectal cancers and estrogen receptor negative breast tumors and androgen receptor negative prostate tumors [46, 47, 49, 123-125]. More specifically, ACSL5 gene expression is consistently elevated in the colon cancer tissue compared to normal colon tissue [49], so are ACSL4 gene expression and protein levels in colon adenocarcinoma compared with adjacent normal tissue [47] and in hepatocellular carcinoma tissues compared to the adjacent noncancerous liver tissue [48]. Finally, ACSL3 expression is elevated in the highly tumorigenic U87 human glioblastoma cell line and cells derived from tumorigenic primary glioblastoma xenografts (Mayo 22) compared with the less tumorigenic U373 glioma cells [46].

Collectively, the results from these studies suggest that expression of ACSLs is related to tumorigenesis and tumor progression. Cell culture loss and gain of function studies provide insight into the relationship between altered intracellular fatty acid metabolism and cancer cell biology. In terms of fatty acid metabolism, both ACSL3 and ACSL5 overexpression in HepG2 cells increase fatty acid oxidation and reduce TAG levels [126]. Supporting the gene expression observations, altered ASCL expression in cancer cells is linked with survival, proliferation, and chemoresistance. For example, overexpressed ACSL4 in human epithelial cells reduced the level of arachidonic acid-induced apoptosis [127], whereas siRNA-mediated ACSL3 knockdown reduced growth rates of lung cancer cell lines and colony formation [124]. Similarly, ACSL4 knockdown inhibited growth rates of the human hepatocellular carcinoma cell line Hep3B [48]. Additionally, pharmacological inhibition of ACS activity by triacsinC induced apoptosis in HEK293 cells [127] and glioma cells, which was completely suppressed by overexpression of ACSL5 [128].

The impact of ASCL expression and function in cancer biology in the obese setting has not been reported. Interestingly, ACSL activity and Acsll gene expression are upregulated in liver and adipose tissues in genetic obese models, including ob/ob mice and Zucker fatty rat (fa/fa) [93, 129] and high-fat fed rats [130]. This suggests that the elevated expression reported may be exacerbated in obesity and therefore may accelerate cancer progression. How changes in ASCL-mediated fatty acid metabolism are linked to altered cancer progression is yet to be fully elucidated. However, Cao and colleagues [127] proposed that changes in proapoptotic arachidonic acid levels may play a role yet other bioactive lipids such as sphingolipids, including ceramides, or changes in fatty acyl-CoA availability for mitochondrial oxidation are potential contributors.

3.2. Fatty Acid Esterification. FAs are the building blocks for many complex lipids including phospholipids, sphingolipids, and glycerolipids. We will focus on the synthesis of glycerolipids, such as TAG, as this is a major pool that is susceptible to the obese environment. The storage of fatty acids as TAG involves several condensation reactions. The first step involves esterifying a fatty acyl-CoA with glycerol3-phosphate to generate lysophosphatidic acid (LPA) by the enzyme glycerol-3-phosphate acyltransferase (GPAT). LPA is then condensed into phosphatidic acid (PA) by 1-acylglycerol-3-phosphate-O-acyltransferase (AGPAT). The subsequent reaction is catalyzed by lipin, which dephosphorylates PA to produce diacylglycerol (DAG). The final step involves the addition of a third fatty acyl-CoA to DAG by diacylglycerol acyltransferase (DGAT) to generate TAG. This process occurs in the endoplasmic reticulum where TAG is packaged into lipid droplets [131]. Alongside the endoplasmic reticulum pathway, there is evidence that DGAT can also catalyze the conversion of DAG to TAG at the lipid droplet [132-134].

The lipid intermediates of the esterification pathway are substrates for the generation of other complex lipids, such as phospholipids in membrane synthesis, and can also act as lipid signals that modify membrane structures and promote gene transcription for cell growth, proliferation, and differentiation [135].

To date, gene or protein expression profiling of GPAT in cancer cells has not been reported. However, it is known that four isoforms of GPATs are expressed in mammals; GPAT1 and GPAT2 are localized in the mitochondria and GPAT3 and GPAT4 in the endoplasmic reticulum [136]. As rate-limiting enzymes of fatty acid esterification, GPATs are key regulators of TAG synthesis [137, 138].

Similarly, little is known about the expression of lipin and DGAT in cancer patients. Mammals have three lipin proteins and two isoforms of DGAT that regulate phospholipid synthesis and lipid storage $[139,140]$. Consequently, these proteins modulate the availability of fatty acid substrates for lipid signaling and metabolism, which may influence cancer progression [141].

The most studied enzyme of lipid esterification in relation to cancer is 1-acylglycerol-3-phosphate-O-acyltransferase (AGPAT). There are 11 known isoforms of AGPAT, which differ by tissue expression and enzymatic activity [137]. There is consistent evidence suggesting a role for AGPATs in cancer cells. For example, AGPAT2 expression is elevated in ovarian cancer patients with aggressive ovarian cancers and associated with reduced overall survival [50-52]. Gene expression of AGPAT11 is also increased in breast and cervical cancers, as well as colorectal cancer [53]. Interestingly, transcriptional expression of AGPAT9, which is highly homologous with AGPAT11, is upregulated in colorectal cancer, but not in breast and cervical cancers [54].

Obesity is characterized by increased levels of TAG stored in tissues such as skeletal muscle, liver, and cardiac muscle [142], which is a consequence of increased esterification rates $[130,143-145]$. Loss and gain of function studies in various tissues provide an insight into the complex regulation of the intracellular lipid environment. For example, AGPAT6 knockout mice have reduced TAG content in brown and white adipose tissue and interestingly altered fatty acid profile of complex lipids, such as DAG and phospholipids with a shift towards the polyunsaturated more than the monounsaturated fatty acids [146]. Similarly, adipose tissue TAG levels are decreased in mice lacking DGAT [147] and both lipin1 and 
lipin3 [148] and protection from high-fat diet induced obesity and associated metabolic perturbations [139, 149]. Finally, GPAT-deficient mice have lower levels of liver and plasma TAG [150]. On the other hand, overexpressions of GPAT1 [151], GPAT4 [152], AGPAT1 [153], lipin1 [154], and DGAT1 [155] all result in increased TAG levels. From this, it is evident that enzymes involved in esterification significantly influence intracellular and extracellular lipid homeostasis. How this translates to pathogenic changes in cancer cells is yet to be described.

3.3. Lipolysis. TAGs, along with cholesterol esters, are stored in lipid droplets to serve as a readily available source of energy for ATP generation in the mitochondria, as well as providing building blocks for phospholipids and other complex lipids. In terms of metabolic energy capacity, an average nonobese person stores up to 2,500 kJ of metabolic energy in glycogen, but $>500,000 \mathrm{~kJ}$ as TAGs [156]. Whilst most of this TAG is stored in adipocytes, all cells have the capacity to synthesize and breakdown TAGs. Interestingly, intracellular lipid stores, or lipid droplet size and/or number, are elevated in various malignant cells, such as breast [157], prostate [158], cervical [159], liver [160], and colon cancer cells [161]. Furthermore, biochemical assessment of lipid droplets in breast cancer cells has shown that the TAG content is increased [162]. Not only that, TAG levels are higher in more aggressive breast cancer cells and are associated with long-term breast cancer cell survival $[157,162]$. These findings suggest that intracellular TAG may play a critical, yet unexplored, role in supporting both substrates for complex lipid synthesis [163] as well as energy production in cancer cells that collectively promote cell growth and proliferation. To do this, TAGs need to be broken down to FAs and glycerol by a process called lipolysis.

ATGL, otherwise known as desnutrin [164], is the predominant TAG lipase that is thought to be rate-limiting [165]. It catalyzes the conversion of TAG to DAG and releases a free fatty acid from the sn-2 position [166]. Hormonesensitive lipase (HSL) catalyzes the hydrolysis of DAG into monoacylglycerol (MAG) and a fatty acid [167]. HSL has broad substrate specificity, including TAG, DAG, MAG, and cholesterol ester lipid classes, but has the highest affinity for DAG [168]. MAG is then broken down by monoacylglycerol lipase (MAGL) resulting in the metabolic end-product, glycerol, and the liberation of the final fatty acid. This process is highly conserved across species and highly regulated with most insight arising from studies in adipocytes (see review [169]).

Adipose neutral lipase expression in various cancer patients has been reported. Compared to normal individuals without cancer, HSL mRNA expression is elevated in adipose tissue of colorectal, pancreatic, esophageal, and stomach cancer patients [57]. This was also observed in ovarian cancer patients, where adipocyte lipid depots which contain TAG were reduced, while the lipolytic products, MAG and free fatty acids, were increased, collectively suggesting elevated lipolytic activity [170]. Similarly, transcriptional and protein expression of HSL are increased in the adipose tissue of latestage cancer patients exhibiting uncontrolled loss of adipose and muscle tissue, known as cachexia [55]. Interestingly, upregulated ATGL activity in adipose tissue was found to be responsible for this tissue-wasting syndrome [56].

MAGL is currently the most well-documented neutral lipase and its transcriptional expression is altered in several different cancers. For example, high mRNA expression of MAGL has been reported in ovarian [59], colorectal [58], breast, and melanoma cancer cells and particularly in aggressive prostate cancer cell lines [59]. Interestingly, in vitro studies overexpressing MAGL in nonaggressive ovarian cancer cells raised free FA levels and increased tumor growth rate, migration, and invasion [171]. Alternatively, pharmacological inhibition attenuated MAGL-induced aggressiveness of prostate cancer cells, even in a high-lipid environment $[59,171]$. Similar observations have been made in colorectal cancer cells [58].

There are conflicting observations regarding the expression patterns of lipolytic enzymes in obesity [172]. HSL and ATGL gene expression are reduced in the adipose tissue of obese humans [173-175] and insulin resistant high-fat fed rats [176]. Conversely, a study by de Naeyer and colleagues [172] has reported that HSL and ATGL mRNA expression are increased in visceral adipose tissue of morbidly obese men; however, this pattern did not translate to changes in protein or lipase activity. This is not surprising considering that these neutral lipases are predominantly regulated by posttranslational modifications, translocation, and proteinprotein interactions [135]. Interestingly, lipolytic enzyme expression, particularly ATGL, appears to be more associated with insulin sensitivity rather than obesity [177]. In order to elucidate the role lipolysis plays in cancer cell biology, future studies need to assess pathway of lipid metabolism and fatty acid flux, rather than gene expression, and investigate how these are altered with obesity.

\section{Mitochondrial Fatty Acid Oxidation}

4.1. Fatty Acid Entry into the Mitochondria. The other major fate for extracellular fatty acids is oxidation for the generation of ATP in the mitochondria. Alongside glucose and glutamine, fatty acids are a major energy source catabolized through the $\beta$-oxidation pathway to generate acetyl-CoA for entry into the TCA cycle as well as $\mathrm{FADH}_{2}$ and $\mathrm{NADH}$ reducing equivalents for use by the electron transport chain (ETC).

Changes in cancer cell fatty acid oxidation have been reported. The primary example is observed in prostate cancer. Rather than being secreted as it is in normal prostate cells, citrate is catabolized in the TCA cycle resulting in fatty acid oxidation being the dominant bioenergetic pathway [178]. Interestingly, high-fat feeding of the p48-Kras mouse model of pancreatic cancer accelerated tumor growth and increased energy expenditure and whole body fatty acid oxidation through increased gene expression of CPT1A, ACC, and AOX enzymes, key regulators of fatty acid oxidation [179].

Few other studies have investigated the effect of obesity on cancer fatty acid oxidation. Although there is significant controversy as to the effect that obesity has on fatty acid oxidation in type 2 diabetes, the increased availability of circulating and intracellular fatty acids is thought to drive an increased 
oxidative capacity. Evidence for this arises from studies in rodents fed a high-fat diet $[124,180]$ and obese type II diabetic patients [181]. Conversely, a number of studies reported a reduced capacity to oxidize fatty acids in overweight/obese humans $[182,183]$. Considering the high metabolic flexibility of cancer cells, it is conceivable that cancer cells benefit from high lipid availability that characterizes obesity through betaoxidation either to fulfill increased energy demand or to prevent the lipotoxic effects of high level of fatty acids.

4.2. Carnitine Palmitoyltransferase 1. Unlike short-chain fatty acids, which can freely diffuse into mitochondria, long-chain fatty acids enter the mitochondria by the carnitine shuttle system. First, carnitine palmitoyltransferase 1 (CPT1) catalyzes the transfer of the fatty acid moiety from acyl-coenzyme A (CoA) to a long-chain acyl-carnitine. This is then transported into the mitochondrial matrix by the carnitine acyl-carnitine translocase (CACT) [184]. CPT2 then catalyzes the conversion of acyl-carnitine to carnitine and fatty acyl-CoA which then enters the $\beta$-oxidation pathway. CPT1 is regulated by a cytosolic pool of malonyl-CoA produced by acetyl-CoA carboxylase 2 (ACC2) at the mitochondrial membrane [185].

The rate of mitochondrial fatty acid oxidation is regulated by CPT1, which is an integral membrane protein located on the mitochondrial outer membrane [186]. CPT1 has three isoforms with tissue-specific expressions and sensitivity to the allosteric-inhibitory action of malonyl-CoA: CPT1A (liver), CPT1B (muscle), and CPT1C (brain) $[187,188]$. Changes in CPT1 expression have been observed in several types of cancer including breast, lung, brain, and liver cancers $[60,62,189$, 190]. A study by Linher-Melville and colleagues [60] reported that CPT1A mRNA levels are significantly elevated in both MCF-7 and MDA-MB-231 cells compared to 184B5 human mammary epithelial cells. In another study, CPT1C gene expression is upregulated in non-small-cell lung carcinoma tumor tissue compared with matched normal lung tissue [62]. Furthermore, high grade glioblastoma is associated with increased mRNA levels of both CPT1A and CPT1C [61]. These studies clearly show that CPT1 expression levels are related to not only tumorigenesis but also tumor progression. In contrast, CPT1 expression has been reported to be higher in the low metastatic potential, androgen receptor negative LNCaP prostate cancer cell line compared to the high metastatic potential, androgen receptor positive PC3 and DU145 prostate cancer cell lines [59]. Overexpression of CPT1C in MCF-7 cell line elevated fatty acid oxidation and ATP production to support resistance to glucose deprivation and siRNA-mediated CPT1C knockdown suppressed xenograft tumor growth [62]. Further evidence for a role for CPT1 in cancer biology has been generated from pharmacological studies. Inhibition of CPT1 with either genetic or pharmacological manipulation has been shown to reduce total ATP levels and the rate of ATP production in PC3 prostate cancer cells [62], Burkitt's lymphoma cells [191], and human glioblastoma cells [192] to impair proliferation. Additionally, etomoxir sensitizes human leukemia cells to apoptosis [193]. Collectively, these studies suggest a role for altered CPT1 expression in various cancers but interestingly CPT1 expression is sensitive to the microenvironment. For example, CPT1A mRNA expression and fatty acid oxidation are increased in SKOV3ipl ovarian cancer cells cocultured with adipocytes [31]. However, it must be highlighted that fatty acid oxidation is regulated at a number of levels including CPT1 gene expression, allosterically by malonylCoA and fatty acid availability.

4.3. Acetyl-CoA Carboxylase. Acetyl-CoA carboxylase is a biotin-dependent enzyme that catalyzes the conversion of acetyl-CoA into malonyl-CoA. In mammals, two isoforms of ACC are expressed: ACC1 (also known as ACC $\alpha$ ) and ACC2 (also known as ACC $\beta$ ) [194]. ACC1 is primarily expressed in the cytosol of hepatocytes, adipocytes, and other lipogenic cells, while ACC2 is an enzyme associated with the outer mitochondrial membrane and is mainly expressed in cardiomyocytes, skeletal muscles, and hepatocytes [195-198]. Whereas the malonyl-CoA generated by ACC1 is primarily used for de novo lipogenesis, the malonyl-CoA product of ACC2 is a potent regulator of fatty acid oxidation by inhibiting CPT1 $[199,200]$. Upstream of ACC2 is AMPactivated protein kinase (AMPK), which phosphorylates and inactivates ACC2 to reduce malonyl-CoA levels and thereby increase fatty acid oxidation.

Upregulation of ACC1 and increased de novo lipogenesis are observed in several types of cancer including breast [63, 64], prostate [65], lung [66], and liver cancers [67]. Chemical and genetic inhibition studies have identified a role for ACC1 in cell survival. For example, apoptotic cell death results from chemical inhibition of ACC1 by TOFA (5-tetradecyloxy-2furoic acid) in lung and colon cancer cells [201] and by soraphen A in prostate cancer cells [202]. In addition, RNA interference- (RNAi-) mediated knockdown of ACC1 induces apoptosis in breast [203] and prostate cancer cells [204].

To date, studies have focused on ACC1, yet few studies have been conducted into the role of ACC2 in cancer development or progression. One of these studies demonstrated that knockdown of ACC2 increased fatty acid oxidation and inhibited cell death in A549 human lung carcinoma cells [205]. Similarly, pharmacological inhibition of malonylCoA decarboxylase (MCD), which increased the malonylCoA pool, suppresses human breast cancer cell proliferation [206]. Therefore, decreasing fatty acid oxidation rates by the modulation of the malonyl-CoA pool by ACC2 and MCD suggests a potential role for these enzymes in cancer metabolism. However, ACC2 functions in other cancer types remain to be elucidated.

The role of ACC2 in obesity is more established. Skeletal muscle ACC2 phosphorylation and activity are reduced in obese patients, as a consequence of reduced AMPK activity [207, 208]. Additionally, the mRNA levels of ACC2 in white adipose tissue are lower in Zucker fatty rats than in lean rats [209]. Interestingly, the AMPK-ACC2-CPT1 axis is modulated by several adipokines, whose levels are altered in obesity. These include leptin [210], adiponectin [211], and CTRP1 [212]. Moreover, recent evidence in liver demonstrates that metformin's actions to suppress de novo lipogenesis and increase fatty acid oxidation require AMPK-mediated phosphorylation of ACC1 and ACC2. Thus, the significant interest in the clinical use of metformin as the therapeutic in 
many cancers will further contribute to the understanding of the role that ACC1/2 plays in cancer biology [213].

\section{Conclusions}

The current interest in cancer metabolism has the potential to identify common perturbations arising from differing genetic origins that may serve as therapeutic targets. As the current obesity epidemic continues to grow, there is a need to not only define cancer metabolism but also investigate how it is influenced by the obese microenvironment. It is clear that cancer fatty acid metabolism plays a significant role in cancer biology and that opportunities exist to further define this role, especially in the context of obesity-induced changes in cancer progression.

\section{Abbreviations}

$\begin{array}{ll}\text { CD36/FAT: } & \text { Cluster of differentiation 36/fatty acid } \\ & \text { translocation } \\ \text { LPL: } & \text { Lipoprotein lipase } \\ \text { VLDL: } & \text { Very-low density lipoprotein } \\ \text { FABP: } & \text { Fatty acid binding protein } \\ \text { PPAR: } & \text { Peroxisome proliferator-activated receptor } \\ \text { FATPs: } & \text { Fatty acid transport proteins } \\ \text { TAG: } & \text { Triacylglycerol } \\ \text { LPA: } & \text { Lysophosphatidic acid } \\ \text { GPAT: } & \text { Glycerol-3-phosphate acyltransferase } \\ \text { AGPAT: } & \text { 1-Acylglycerol-3-phosphate-O- } \\ & \text { acyltransferase } \\ \text { DAG: } & \text { Diacylglycerol } \\ \text { HSL: } & \text { Hormone-sensitive lipase } \\ \text { MAG: } & \text { Monoacylglycerol } \\ \text { MAGL: } & \text { Monoacylglycerol lipase } \\ \text { ATGL: } & \text { Adipose triglyceride lipase } \\ \text { ACS: } & \text { Acyl-CoA synthetase } \\ \text { CPT1: } & \text { Carnitine palmitoyltransferase 1 } \\ \text { CoA: } & \text { Coenzyme A } \\ \text { ETC: } & \text { Electron transport chain } \\ \text { ACSL: } & \text { Acyl-CoA synthetase long-chain family. }\end{array}$

\section{Conflict of Interests}

The authors declare that there is no conflict of interests regarding the publication of this paper.

\section{Acknowledgments}

Andrew J. Hoy is supported by Helen and Robert Ellis Postdoctoral Research Fellowship and funding from the University of Sydney. Seher Balaban is a recipient of a University of Sydney Australian Postgraduate Award. Mark Schreuder is supported by funding from the Dutch Cancer Institute KWF.

\section{References}

[1] S. M. Grundy, "Obesity, metabolic syndrome, and cardiovascular disease," Journal of Clinical Endocrinology and Metabolism, vol. 89, no. 6, pp. 2595-2600, 2004.
[2] S. M. Louie, L. S. Roberts, and D. K. Nomura, "Mechanisms linking obesity and cancer," Biochimica et Biophysica Acta: Molecular and Cell Biology of Lipids, vol. 1831, no. 10, pp. 14991508, 2013.

[3] K. Y. Wolin, K. Carson, and G. A. Colditz, "Obesity and cancer," Oncologist, vol. 15, no. 6, pp. 556-565, 2010.

[4] G. de Pergola and F. Silvestris, "Obesity as a major risk factor for cancer," Journal of Obesity, vol. 2013, Article ID 291546, 11 pages, 2013.

[5] W. C. Buschemeyer III and S. J. Freedland, "Obesity and prostate cancer: epidemiology and clinical implications," European Urology, vol. 52, no. 2, pp. 331-343, 2007.

[6] B. Majed, T. Moreau, K. Senouci, R. J. Salmon, A. Fourquet, and B. Asselain, "Is obesity an independent prognosis factor in woman breast cancer?" Breast Cancer Research and Treatment, vol. 111, no. 2, pp. 329-342, 2008.

[7] Y. Zhu, H.-K. Wang, H.-L. Zhang et al., "Visceral obesity and risk of high grade disease in clinical Tla renal cell carcinoma," The Journal of Urology, vol. 189, no. 2, pp. 447-453, 2013.

[8] A. Ansary-Moghaddam, R. Huxley, F. Barzi et al., "The effect of modifiable risk factors on pancreatic cancer mortality in populations of the Asia-Pacific region," Cancer Epidemiology Biomarkers and Prevention, vol. 15, no. 12, pp. 2435-2440, 2006.

[9] C. A. Gilbert and J. M. Slingerland, "Cytokines, obesity, and cancer: new insights on mechanisms linking obesity to cancer risk and progression," Annual Review of Medicine, vol. 64, pp. 45-57, 2013.

[10] J. K. Sethi and A. J. Vidal-Puig, "Thematic review series: adipocyte Biology. Adipose tissue function and plasticity orchestrate nutritional adaptation," Journal of Lipid Research, vol. 48, no. 6, pp. 1253-1262, 2007.

[11] D. Samocha-Bonet, D. J. Chisholm, K. Tonks, L. V. Campbell, and J. R. Greenfield, "Insulin-sensitive obesity in humansa "favorable fat" phenotype?" Trends in Endocrinology \& Metabolism, vol. 23, no. 3, pp. 116-124, 2012.

[12] N. Ruderman, D. Chisholm, X. Pi-Sunyer, and S. Schneider, "The metabolically obese, normal-weight individual revisited," Diabetes, vol. 47, no. 5, pp. 699-713, 1998.

[13] R. Kelishadi, S. R. Cook, M. E. Motlagh et al., "Metabolically obese normal weight and phenotypically obese metabolically normal youths: the CASPIAN Study," Journal of the American Dietetic Association, vol. 108, no. 1, pp. 82-90, 2008.

[14] T. Nolis, "Exploring the pathophysiology behind the more common genetic and acquired lipodystrophies," Journal of Human Genetics, vol. 59, no. 1, pp. 16-23, 2014.

[15] J. Capeau, J. Magré, M. Caron-Debarle et al., "Human lipodystrophies: genetic and acquired diseases of adipose tissue," Endocrine Development, vol. 19, pp. 1-20, 2010.

[16] M. J. Khandekar, P. Cohen, and B. M. Spiegelman, "Molecular mechanisms of cancer development in obesity," Nature Reviews Cancer, vol. 11, no. 12, pp. 886-895, 2011.

[17] S. Narita, N. Tsuchiya, L. Wang et al., "Association of lipoprotein lipase gene polymorphism with risk of prostate cancer in a Japanese population," International Journal of Cancer, vol. 112, no. 5, pp. 872-876, 2004.

[18] J. C. Carter and F. C. Church, "Mature breast adipocytes promote breast cancer cell motility," Experimental and Molecular Pathology, vol. 92, no. 3, pp. 312-317, 2012.

[19] K. Sakayama, H. Masuno, T. Miyazaki, H. Okumura, T. Shibata, and H. Okuda, "Existence of lipoprotein lipase in human sarcomas and carcinomas," Japanese Journal of Cancer Research, vol. 85 , no. 5, pp. 515-521, 1994. 
[20] D. Cerne, I. P. Zitnik, and M. Sok, "Increased fatty acid synthase activity in non-small cell lung cancer tissue is a weaker predictor of shorter patient survival than increased lipoprotein lipase activity," Archives of Medical Research, vol. 41, no. 6, pp. 405409, 2010.

[21] Z. Trost, M. Sok, J. Marc, and D. Cerne, "Increased lipoprotein lipase activity in non-small cell lung cancer tissue predicts shorter patient survival," Archives of Medical Research, vol. 40, no. 5, pp. 364-368, 2009.

[22] S. M. Rachidi, T. Qin, S. Sun, W. J. Zheng, and Z. Li, "Molecular profiling of multiple human cancers defines an inflammatory cancer-associated molecular pattern and uncovers KPNA2 as a uniform poor prognostic cancer marker," PLoS ONE, vol. 8, no. 3, Article ID e57911, 2013.

[23] I. P. Uray, Y. Liang, and S. M. Hyder, "Estradiol down-regulates CD36 expression in human breast cancer cells," Cancer Letters, vol. 207, no. 1, pp. 101-107, 2004.

[24] D. E. Blask, L. A. Sauer, R. T. Dauchy, E. W. Holowachuk, M. S. Ruhoff, and H. S. Kopff, "Melatonin inhibition of cancer growth in vivo involves suppression of tumor fatty acid metabolism via melatonin receptor-mediated signal transduction events," Cancer Research, vol. 59, no. 18, pp. 4693-4701, 1999.

[25] R. Hammamieh, N. Chakraborty, M. Barmada, R. Das, and M. Jett, "Expression patterns of fatty acid binding proteins in breast cancer cells," Journal of Experimental Therapeutics and Oncology, vol. 5, no. 2, pp. 133-143, 2005.

[26] A. Tölle, S. Suhail, M. Jung, K. Jung, and C. Stephan, "Fatty acid binding proteins (FABPs) in prostate, bladder and kidney cancer cell lines and the use of IL-FABP as survival predictor in patients with renal cell carcinoma," BMC cancer, vol. 11, article 302, 2011.

[27] J. E. Celis, M. Østergaard, B. Basse et al., "Loss of adipocytetype fatty acid binding protein and other protein biomarkers is associated with progression of human bladder transitional cell carcinomas," Cancer Research, vol. 56, no. 20, pp. 4782-4790, 1996.

[28] G. Ohlsson, J. M. A. Moreira, P. Gromov, G. Sauter, and J. E. Celis, "Loss of expression of the adipocyte-type fatty acidbinding protein $(\mathrm{A}-\mathrm{FABP})$ is associated with progression of human urothelial carcinomas," Molecular \& Cellular Proteomics, vol. 4, no. 4, pp. 570-581, 2005.

[29] P. J. Wild, A. Herr, C. Wissmann et al., "Gene expression profiling of progressive papillary noninvasive carcinomas of the urinary bladder," Clinical Cancer Research, vol. 11, no. 12, pp. 4415-4429, 2005.

[30] M. K. Herroon, E. Rajagurubandara, A. L. Hardaway et al., "Bone marrow adipocytes promote tumor growth in bone via FABP4-dependent mechanisms," Oncotarget, vol. 4, no. 11, pp. 2108-2123, 2013.

[31] K. M. Nieman, H. A. Kenny, C. V. Penicka et al., "Adipocytes promote ovarian cancer metastasis and provide energy for rapid tumor growth," Nature Medicine, vol. 17, no. 11, pp. 1498-1503, 2011.

[32] C. Jing, C. Beesley, C. S. Foster et al., "Identification of the messenger RNA for human cutaneous fatty acid-binding protein as a metastasis inducer," Cancer Research, vol. 60, no. 9, pp. 2390-2398, 2000.

[33] R.-Z. Liu, K. Graham, D. D. Glubrecht, D. R. Germain, J. R. Mackey, and R. Godbout, "Association of FABP5 expression with poor survival in triple-negative breast cancer: implication for retinoic acid therapy," The American Journal of Pathology, vol. 178, no. 3, pp. 997-1008, 2011.
[34] Z. Li, C. Huang, S. Bai et al., "Prognostic evaluation of epidermal fatty acid-binding protein and calcyphosine, two proteins implicated in endometrial cancer using a proteomic approach," International Journal of Cancer, vol. 123, no. 10, pp. 2377-2383, 2008.

[35] K. Fujii, T. Kondo, H. Yokoo, T. Yamada, K. Iwatsuki, and S. Hirohashi, "Proteomic study of human hepatocellular carcinoma using two-dimensional difference gel electrophoresis with saturation cysteine dye," Proteomics, vol. 5, no. 5, pp. 14111422, 2005.

[36] P. Sinha, G. Hütter, E. Köttgen, M. Dietel, D. Schadendorf, and H. Lage, "Increased expression of epidermal fatty acid binding protein, cofilin, and 14-3-3-sigma (stratifin) detected by two-dimensional gel electrophoresis, mass spectrometry and microsequencing of drug-resistant human adenocarcinoma of the pancreas," Electrophoresis, vol. 20, no. 14, pp. 2952-2960, 1999.

[37] Z. Bao, M. I. Malki, S. S. Forootan et al., "A novel cutaneous Fatty Acid-binding protein-related signaling pathway leading to malignant progression in prostate cancer cells," Genes and Cancer, vol. 4, no. 7-8, pp. 297-314, 2013.

[38] R. Das, R. Hammamieh, R. Neill, M. Melhem, and M. Jett, "Expression pattern of fatty acid-binding proteins in human normal and cancer prostate cells and tissues," Clinical Cancer Research, vol. 7, no. 6, pp. 1706-1715, 2001.

[39] J. Adamson, E. A. Morgan, C. Beesley et al., "High-level expression of cutaneous fatty acid-binding protein in prostatic carcinomas and its effect on tumorigenicity," Oncogene, vol. 22, no. 18, pp. 2739-2749, 2003.

[40] X. Y. Tang, S. Umemura, H. Tsukamoto, N. Kumaki, Y. Tokuda, and R. Y. Osamura, "Overexpression of fatty acid binding protein-7 correlates with basal-like subtype of breast cancer," Pathology Research and Practice, vol. 206, no. 2, pp. 98-101, 2010.

[41] H. Zhang, E. A. Rakha, G. R. Ball et al., "The proteins FABP7 and OATP2 are associated with the basal phenotype and patient outcome in human breast cancer," Breast Cancer Research and Treatment, vol. 121, no. 1, pp. 41-51, 2010.

[42] A. T. Alshareeda, E. A. Rakha, C. C. Nolan, I. O. Ellis, and A. R. Green, "Fatty acid binding protein 7 expression and its subcellular localization in breast cancer," Breast Cancer Research and Treatment, vol. 134, no. 2, pp. 519-529, 2012.

[43] Y. Goto, K. Koyanagi, N. Narita et al., "Aberrant fatty acidbinding protein-7 gene expression in cutaneous malignant melanoma," Journal of Investigative Dermatology, vol. 130, no. 1, pp. 221-229, 2010.

[44] C. Tan, T. Takayama, N. Takaoka et al., "Impact of gender in renal cell carcinoma: the relationship of FABP7 and BRN2 expression with overall survival," Clinical Medicine Insights: Oncology, vol. 8, pp. 21-27, 2014.

[45] T. Teratani, T. Domoto, K. Kuriki et al., "Detection of transcript for brain-type fatty acid-binding protein in tumor and urine of patients with renal cell carcinoma," Urology, vol. 69, no. 2, pp. 236-240, 2007.

[46] Z. Pei, P. Sun, P. Huang, B. Lal, J. Laterra, and P. A. Watkins, "Acyl-CoA synthetase VL3 knockdown inhibits human glioma cell proliferation and tumorigenicity," Cancer Research, vol. 69, no. 24, pp. 9175-9182, 2009.

[47] Y. Cao, K. B. Dave, T. P. Doan, and S. M. Prescott, "Fatty acid CoA ligase 4 is up-regulated in colon adenocarcinoma," Cancer Research, vol. 61, no. 23, pp. 8429-8434, 2001.

[48] Y.-C. Liang, C.-H. Wu, J.-S. Chu et al., "Involvement of fatty acid-CoA ligase 4 in hepatocellular carcinoma growth: roles of 
cyclic AMP and p38 mitogen-activated protein kinase," World Journal of Gastroenterology, vol. 11, no. 17, pp. 2557-2563, 2005.

[49] C.-S. Yeh, J.-Y. Wang, T.-L. Cheng, C.-H. Juan, C.-H. Wu, and S.R. Lin, "Fatty acid metabolism pathway play an important role in carcinogenesis of human colorectal cancers by MicroarrayBioinformatics analysis," Cancer Letters, vol. 233, no. 2, pp. 297308, 2006.

[50] C. S. M. Diefenbach, R. A. Soslow, A. Iasonos et al., "Lysophosphatidic acid acyltransferase- $\beta$ (LPAAT- $\beta$ ) is highly expressed in advanced ovarian cancer and is associated with aggressive histology and poor survival," Cancer, vol. 107, no. 7, pp. 1511-1519, 2006.

[51] S. Niesporek, C. Denkert, W. Weichert et al., "Expression of lysophosphatidic acid acyltransferase beta (LPAAT-beta) in ovarian carcinoma: correlation with tumour grading and prognosis," British Journal of Cancer, vol. 92, no. 9, pp. 17291736, 2005.

[52] G. M. Springett, L. Bonham, A. Hummer et al., "Lysophosphatidic acid acyltransferase-beta is a prognostic marker and therapeutic target in gynecologic malignancies," Cancer Research, vol. 65, no. 20, pp. 9415-9425, 2005.

[53] A. K. Agarwal and A. Garg, "Enzymatic activity of the human 1acylglycerol-3-phosphate-O-acyltransferase isoform 11: upregulated in breast and cervical cancers," Journal of Lipid Research, vol. 51, no. 8, pp. 2143-2152, 2010.

[54] F. Mansilla, K.-A. Da Costa, S. Wang et al., "Lysophosphatidylcholine acyltransferase 1 (LPCAT1) overexpression in human colorectal cancer," Journal of Molecular Medicine, vol. 87, no. 1, pp. 85-97, 2009.

[55] T. Agustsson, M. Rydén, J. Hoffstedt et al., "Mechanism of increased lipolysis in cancer cachexia," Cancer Research, vol. 67, no. 11, pp. 5531-5537, 2007.

[56] S. K. Das, S. Eder, S. Schauer et al., "Adipose triglyceride lipase contributes to cancer-associated cachexia," Science, vol. 333, no. 6039, pp. 233-238, 2011.

[57] M. P. Thompson, S. T. Cooper, B. R. Parry, and J. A. Tuckey, "Increased expression of the mRNA for hormone-sensitive lipase in adipose tissue of cancer patients," Biochimica et Biophysica Acta, vol. 1180, no. 3, pp. 236-242, 1993.

[58] L. Ye, B. Zhang, E. G. Seviour et al., "Monoacylglycerol lipase (MAGL) knockdown inhibits tumor cells growth in colorectal cancer," Cancer Letters, vol. 307, no. 1, pp. 6-17, 2011.

[59] D. K. Nomura, D. P. Lombardi, J. W. Chang et al., "Monoacylglycerol lipase exerts dual control over endocannabinoid and fatty acid pathways to support prostate cancer," Chemistry and Biology, vol. 18, no. 7, pp. 846-856, 2011.

[60] K. Linher-Melville, S. Zantinge, T. Sanli, H. Gerstein, T. Tsakiridis, and G. Singh, "Establishing a relationship between prolactin and altered fatty acid $\beta$-oxidation via carnitine palmitoyl transferase 1 in breast cancer cells," BMC Cancer, vol. 11, article 56, 2011.

[61] A. Cirillo, A. Di Salle, O. Petillo et al., "High grade glioblastoma is associated with aberrant expression of ZFP57, a protein involved in gene imprinting, and of CPT1A and CPT1C that regulate fatty acid metabolism," Cancer Biology and Therapy, vol. 15, no. 6, pp. 735-741, 2014.

[62] K. Zaugg, Y. Yao, P. T. Reilly et al., "Carnitine palmitoyltransferase 1C promotes cell survival and tumor growth under conditions of metabolic stress," Genes \& Development, vol. 25, no. 10, pp. 1041-1051, 2011.

[63] L. Z. Milgraum, L. A. Witters, G. R. Pasternack, and F. P. Kuhajda, "Enzymes of the fatty acid synthesis pathway are highly expressed in in situ breast carcinoma," Clinical Cancer Research, vol. 3, no. 11, pp. 2115-2120, 1997.

[64] J. T. Moncur, J. P. Park, V. A. Memoli, T. K. Mohandas, and W. B. Kinlaw, "The "Spot 14" gene resides on the telomeric end of the 11q13 amplicon and is expressed in lipogenic breast cancers: implications for control of tumor metabolism," Proceedings of the National Academy of Sciences of the United States of America, vol. 95, no. 12, pp. 6989-6994, 1998.

[65] J. V. Swinnen, F. Vanderhoydonc, A. A. Elgamal et al., "Selective activation of the fatty acid synthesis pathway in human prostate cancer," International Journal of Cancer, vol. 88, no. 2, pp. 176179, 2000.

[66] E. Conde, A. Suarez-Gauthier, E. García-García et al., "Specific pattern of LKB1 and phospho-acetyl-CoA carboxylase protein immunostaining in human normal tissues and lung carcinomas," Human Pathology, vol. 38, no. 9, pp. 1351-1360, 2007.

[67] N. Yahagi, H. Shimano, K. Hasegawa et al., "Co-ordinate activation of lipogenic enzymes in hepatocellular carcinoma," European Journal of Cancer, vol. 41, no. 9, pp. 1316-1322, 2005.

[68] H. Wong and M. C. Schotz, "The lipase gene family," Journal of Lipid Research, vol. 43, no. 7, pp. 993-999, 2002.

[69] H. Podgornik, M. Sok, I. Kern, J. Marc, and D. Cerne, "Lipoprotein lipase in non-small cell lung cancer tissue is highly expressed in a subpopulation of tumor-associated macrophages," Pathology-Research and Practice, vol. 209, no. 8, pp. 516-520, 2013.

[70] S. Kersten, "Physiological regulation of lipoprotein lipase," Biochimica et Biophysica Acta: Molecular and Cell Biology of Lipids, vol. 1841, no. 7, pp. 919-933, 2014.

[71] J. F. F. Brinkmann, N. A. Abumrad, A. Ibrahimi, G. J. Van der Vusse, and J. F. C. Glatz, "New insights into long-chain fatty acid uptake by heart muscle: a crucial role for fatty acid translocase/CD36," Biochemical Journal, vol. 367, no. 3, pp. 561$570,2002$.

[72] A. Bonen, A. Chabowski, J. J. F. P. Luiken, and J. F. C. Glatz, "Is membrane transport of FFA mediated by lipid, protein, or both? Mechanisms and regulation of protein-mediated cellular fatty acid uptake: molecular, biochemical, and physiological evidence," Physiology, vol. 22, pp. 15-29, 2007.

[73] D. Hirsch, A. Stahl, and H. F. Lodish, "A family of fatty acid transporters conserved from mycobacterium to man," Proceedings of the National Academy of Sciences of the United States of America, vol. 95, no. 15, pp. 8625-8629, 1998.

[74] J. G. Nickerson, H. Alkhateeb, C. R. Benton et al., "Greater transport efficiencies of the membrane fatty acid transporters FAT/CD36 and FATP4 compared with FABPpm and FATP1 and differential effects on fatty acid esterification and oxidation in rat skeletal muscle," The Journal of Biological Chemistry, vol. 284, no. 24, pp. 16522-16530, 2009.

[75] Q. Wu, A. M. Ortegon, B. Tsang, H. Doege, K. R. Feingold, and A. Stahl, "FATP1 is an insulin-sensitive fatty acid transporter involved in diet-induced obesity," Molecular and Cellular Biology, vol. 26, no. 9, pp. 3455-3467, 2006.

[76] L. Love-Gregory and N. A. Abumrad, "CD36 genetics and the metabolic complications of obesity," Current Opinion in Clinical Nutrition and Metabolic Care, vol. 14, no. 6, pp. 527-534, 2011.

[77] A. S. Asch, J. Barnwell, R. L. Silverstein, and R. L. Nachman, "Isolation of the thrombospondin membrane receptor," The Journal of Clinical Investigation, vol. 79, no. 4, pp. 1054-1061, 1987. 
[78] N. N. Tandon, U. Kralisz, and G. A. Jamieson, "Identification of glycoprotein IV (CD36) as a primary receptor for plateletcollagen adhesion," The Journal of Biological Chemistry, vol. 264, no. 13, pp. 7576-7583, 1989.

[79] G. Endemann, L. W. Stanton, K. S. Madden, C. M. Bryant, R. T. White, and A. A. Protter, "CD36 is a receptor for oxidized low density lipoprotein," The Journal of Biological Chemistry, vol. 268, no. 16, pp. 11811-11816, 1993.

[80] A. G. S. Baillie, C. T. Coburn, and N. A. Abumrad, "Reversible binding of long-chain fatty acids to purified FAT, the adipose CD36 homolog," The Journal of Membrane Biology, vol. 153, no. 1, pp. 75-81, 1996.

[81] D. M. Muoio, G. L. Dohm, E. B. Tapscott, and R. A. Coleman, "Leptin opposes insulin's effects on fatty acid partitioning in muscles isolated from obese ob/ob mice," The American Journal of Physiology-Endocrinology and Metabolism, vol. 276, no. 5, part 1, pp. E913-E921, 1999.

[82] J. F. C. Glatz, A. Bonen, and J. J. F. P. Luiken, "Exercise and insulin increase muscle fatty acid uptake by recruiting putative fatty acid transporters to the sarcolemma," Current Opinion in Clinical Nutrition and Metabolic Care, vol. 5, no. 4, pp. 365-370, 2002.

[83] X. Buqué, M. J. Martínez, A. Cano et al., "A subset of dysregulated metabolic and survival genes is associated with severity of hepatic steatosis in obese Zucker rats," Journal of Lipid Research, vol. 51, no. 3, pp. 500-513, 2010.

[84] A. Bonen, C. R. Benton, S. E. Campbell et al., "Plasmalemmal fatty acid transport is regulated in heart and skeletal muscle by contraction, insulin and leptin, and in obesity and diabetes," Acta Physiologica Scandinavica, vol. 178, no. 4, pp. 347-356, 2003.

[85] J. Smith, X. Su, R. El-Maghrabi, P. D. Stahl, and N. A. Abumrad, "Opposite regulation of CD36 ubiquitination by fatty acids and insulin: effects on fatty acid uptake," The Journal of Biological Chemistry, vol. 283, no. 20, pp. 13578-13585, 2008.

[86] Y. Angin, L. K. M. Steinbusch, P. J. Simons et al., "CD36 inhibition prevents lipid accumulation and contractile dysfunction in rat cardiomyocytes," Biochemical Journal, vol. 448, no. 1, pp. 43-53, 2012.

[87] A. Chabowski, S. L. M. Coort, J. Calles-Escandon et al., "Insulin stimulates fatty acid transport by regulating expression of FAT/CD36 but not FABPpm," American Journal of Physiology: Endocrinology and Metabolism, vol. 287, no. 4, pp. E781-E789, 2004.

[88] N. J. Bryant, R. Govers, and D. E. James, "Regulated transport of the glucose transporter GLUT4," Nature Reviews Molecular Cell Biology, vol. 3, no. 4, pp. 267-277, 2002.

[89] J. W. Slot, H. J. Geuze, S. Gigengack, D. E. James, and G. E. Lienhard, "Translocation of the glucose transporter GLUT4 in cardiac myocytes of the rat," Proceedings of the National Academy of Sciences of the United States of America, vol. 88, no. 17, pp. 7815-7819, 1991.

[90] I. N. Hines, H. J. Hartwell, Y. Feng et al., "Insulin resistance and metabolic hepatocarcinogenesis with parent-of-origin effects in $\mathrm{A} \times \mathrm{B}$ mice," The American Journal of Pathology, vol. 179, no. 6, pp. 2855-2865, 2011.

[91] L. P. Bechmann, R. K. Gieseler, J.-P. Sowa et al., "Apoptosis is associated with CD36/fatty acid translocase upregulation in non-alcoholic steatohepatitis," Liver International, vol. 30, no. 6, pp. 850-859, 2010.

[92] A. Bonen, N. N. Tandon, J. F. C. Glatz, J. J. F. P. Luiken, and G. J. F. Heigenhauser, "The fatty acid transporter FAT/CD36 is upregulated in subcutaneous and visceral adipose tissues in human obesity and type 2 diabetes," International Journal of Obesity, vol. 30, no. 6, pp. 877-883, 2006.

[93] R. A. Memon, J. Fuller, A. H. Moser, P. J. Smith, C. Grunfeld, and K. R. Feingold, "Regulation of putative fatty acid transporters and Acyl-CoA synthetase in liver and adipose tissue in ob/ob mice," Diabetes, vol. 48, no. 1, pp. 121-127, 1999.

[94] A. Taube, S. Lambernd, G. van Echten-Deckert, K. Eckardt, and J. Eckel, "Adipokines promote lipotoxicity in human skeletal muscle cells," Archives of Physiology and Biochemistry, vol. 118, no. 3, pp. 92-101, 2012.

[95] S. El Akoum, I. Cloutier, and J.-F. Tanguay, "Vascular smooth muscle cell alterations triggered by mice adipocytes: role of high-fat diet," Journal of Atherosclerosis and Thrombosis, vol. 19, no. 12, pp. 1128-1141, 2012.

[96] M. Anan, K. Uchihashi, S. Aoki et al., "A promising culture model for analyzing the interaction between adipose tissue and cardiomyocytes," Endocrinology, vol. 152, no. 4, pp. 1599-1605, 2011.

[97] R. Gandhi, M. Takahashi, C. Virtanen, K. Syed, J. R. Davey, and N. N. Mahomed, "Microarray analysis of the infrapatellar fat pad in knee osteoarthritis: relationship with joint inflammation," Journal of Rheumatology, vol. 38, no. 9, pp. 1966-1972, 2011.

[98] C. W. Wu, E. S. H. Chu, C. N. Y. Lam et al., "PPAR $\gamma$ is essential for protection against nonalcoholic steatohepatitis," Gene Therapy, vol. 17, no. 6, pp. 790-798, 2010.

[99] A. Stahl, "A current review of fatty acid transport proteins (SLC27)," Pflugers Archiv European Journal of Physiology, vol. 447, no. 5, pp. 722-727, 2004.

[100] J. Pohl, A. Ring, T. Hermann, and W. Stremmel, "Role of FATP in parenchymal cell fatty acid uptake," Biochimica et Biophysica Acta, vol. 1686, no. 1-2, pp. 1-6, 2004.

[101] R. E. Gimeno, "Fatty acid transport proteins," Current Opinion in Lipidology, vol. 18, no. 3, pp. 271-266, 2007.

[102] C. M. Anderson and A. Stahl, "SLC27 fatty acid transport proteins," Molecular Aspects of Medicine, vol. 34, no. 2-3, pp. 516-528, 2013.

[103] H. Doege and A. Stah, "Protein-mediated fatty acid uptake: novel insights from in vivo models," Physiology, vol. 21 , no. 4 , pp. 259-268, 2006.

[104] H. Schneider, S. Staudacher, M. Poppelreuther, W. Stremmel, R. Ehehalt, and J. Füllekrug, "Protein mediated fatty acid uptake: synergy between CD36/FAT-facilitated transport and acyl-CoA synthetase-driven metabolism," Archives of Biochemistry and Biophysics, vol. 546, pp. 8-18, 2014.

[105] J. F. Bower, J. M. Davis, E. Hao, and H. A. Barakat, "Differences in transport of fatty acids and expression of fatty acid transporting proteins in adipose tissue of obese black and white women," The American Journal of Physiology - Endocrinology and Metabolism, vol. 290, no. 1, pp. E87-E91, 2006.

[106] K. Gertow, K. H. Pietiläinen, H. Yki-Järvinen et al., "Expression of fatty-acid-handling proteins in human adipose tissue in relation to obesity and insulin resistance," Diabetologia, vol. 47, no. 6, pp. 1118-1125, 2004.

[107] H.-C. Chiu, A. Kovacs, R. M. Blanton et al., "Transgenic expression of fatty acid transport protein 1 in the heart causes lipotoxic cardiomyopathy," Circulation Research, vol. 96, no. 2, pp. 225-233, 2005.

[108] M. Marotta, A. Ferrer-Martínez, J. Parnau, M. Turini, K. MacÉ, and A. M. Gómez Foix, "Fiber type- and fatty acid 
composition-dependent effects of high-fat diets on rat muscle triacylglyceride and fatty acid transporter protein-1 content," Metabolism: Clinical and Experimental, vol. 53, no. 8, pp. 10321036, 2004.

[109] P. D. Berk, S.-L. Zhou, C.-L. Kiang, D. Stump, M. Bradbury, and L. M. Isola, "Uptake of long chain free fatty acids is selectively up-regulated in adipocytes of zucker rats with genetic obesity and non-insulin-dependent diabetes mellitus," The Journal of Biological Chemistry, vol. 272, no. 13, pp. 8830-8835, 1997.

[110] P. Besnard, I. Niot, H. Poirier, L. Clément, and A. Bernard, "New insights into the fatty acid-binding protein (FABP) family in the small intestine," Molecular and Cellular Biochemistry, vol. 239, no. 1-2, pp. 139-147, 2002.

[111] A. Chmurzyńska, "The multigene family of fatty acid-binding proteins (FABPs): function, structure and polymorphism," Journal of Applied Genetics, vol. 47, no. 1, pp. 39-48, 2006.

[112] R. M. Kaikaus, N. M. Bass, and R. K. Ockner, "Functions of fatty acid binding proteins," Experientia, vol. 46, no. 6, pp. 617-630, 1990.

[113] A. W. Zimmerman and J. H. Veerkamp, "New insights into the structure and function of fatty acid-binding proteins," Cellular and Molecular Life Sciences, vol. 59, no. 7, pp. 1096-1116, 2002.

[114] Y. Goto, Y. Matsuzaki, S. Kurihara et al., "A new melanoma antigen fatty acid-binding protein 7 , involved in proliferation and invasion, is a potential target for immunotherapy and molecular target therapy," Cancer Research, vol. 66, no. 8, pp. 4443-4449, 2006.

[115] C. Wolfrum, C. M. Borrmann, T. Börchers, and F. Spener, "Fatty acids and hypolipidemic drugs regulate peroxisome proliferator-activated receptors $\alpha$ - and $\gamma$-mediated gene expression via liver fatty acid binding protein: a signaling path to the nucleus," Proceedings of the National Academy of Sciences of the United States of America, vol. 98, no. 5, pp. 2323-2328, 2001.

[116] N. H. Haunerland and F. Spener, "Fatty acid-binding proteinsinsights from genetic manipulations," Progress in Lipid Research, vol. 43, no. 4, pp. 328-349, 2004.

[117] L. A. Afman and M. Müller, "Human nutrigenomics of gene regulation by dietary fatty acids," Progress in Lipid Research, vol. 51, no. 1, pp. 63-70, 2012.

[118] J. Justesen, K. Stenderup, E. N. Ebbesen, L. Mosekilde, T. Steiniche, and M. Kassem, "Adipocyte tissue volume in bone marrow is increased with aging and in patients with osteoporosis," Biogerontology, vol. 2, no. 3, pp. 165-171, 2001.

[119] D. G. Mashek, L. O. Li, and R. A. Coleman, "Long-chain acylCoA synthetases and fatty acid channeling," Future Lipidology, vol. 2, no. 4, pp. 465-476, 2007.

[120] J. A. Kanaley, S. Shadid, M. T. Sheehan, Z. Guo, and M. D. Jensen, "Relationship between plasma free fatty acid, intramyocellular triglycerides and long-chain acylcarnitines in resting humans," Journal of Physiology, vol. 587, part 24, pp. 5939-5950, 2009.

[121] S. M. Turpin, A. J. Hoy, R. D. Brown et al., "Adipose triacylglycerol lipase is a major regulator of hepatic lipid metabolism but not insulin sensitivity in mice," Diabetologia, vol. 54, no. 1, pp. 146-156, 2011.

[122] R. A. Coleman and D. P. Lee, "Enzymes of triacylglycerol synthesis and their regulation," Progress in Lipid Research, vol. 43, no. 2, pp. 134-176, 2004.

[123] M. E. Monaco, C. J. Creighton, P. Lee, X. Zou, M. K. Topham, and D. M. Stafforini, "Expression of long-chain fatty Acyl-CoA synthetase 4 in breast and prostate cancers is associated with sex steroid hormone receptor negativity," Translational Oncology, vol. 3, no. 2, pp. 91-98, 2010.

[124] Z. Pei, P. Fraisl, X. Shi et al., "Very long-chain acyl-CoA synthetase 3: overexpression and growth dependence in lung cancer," PLoS ONE, vol. 8, no. 7, Article ID e69392, 2013.

[125] K. S. Young, K. P. Mi, H. H. Su et al., "Regulation of cell growth by fatty acid-CoA ligase 4 in human hepatocellular carcinoma cells," Experimental and Molecular Medicine, vol. 39, no. 4, pp. 477-482, 2007.

[126] Y. Zhou, P. Abidi, A. Kim et al., "Transcriptional activation of hepatic ACSL3 and ACSL5 by oncostatin M reduces hypertriglyceridemia through enhanced $\beta$-oxidation," Arteriosclerosis, Thrombosis, and Vascular Biology, vol. 27, no. 10, pp. 21982205, 2007.

[127] Y. Cao, A. T. Pearman, G. A. Zimmerman, T. M. McIntyre, and S. M. Prescott, "Intracellular unesterified arachidonic acid signals apoptosis," Proceedings of the National Academy of Sciences of the United States of America, vol. 97, no. 21, pp. 11280$11285,2000$.

[128] T. Mashima, S. Sato, S. Okabe et al., "Acyl-CoA synthetase as a cancer survival factor: its inhibition enhances the efficacy of etoposide," Cancer Science, vol. 100, no. 8, pp. 1556-1562, 2009.

[129] I. Shimomura, K. Tokunaga, S. Jiao et al., "Marked enhancement of acyl-CoA synthetase activity and mRNA, paralleled to lipoprotein lipase mRNA, in adipose tissues of Zucker obese rats (fa/fa)," Biochimica et Biophysica Acta, vol. 1124, no. 2, pp. 112-118, 1992.

[130] B. D. Hegarty, G. J. Cooney, E. W. Kraegen, and S. M. Furler, "Increased efficiency of fatty acid uptake contributes to lipid accumulation in skeletal muscle of high fat-fed insulin-resistant rats," Diabetes, vol. 51, no. 5, pp. 1477-1484, 2002.

[131] V. K. Khor, W. J. Shen, and F. B. Kraemer, "Lipid droplet metabolism," Current Opinion in Clinical Nutrition and Metabolic Care, vol. 16, no. 6, pp. 632-637, 2013.

[132] S. Cases, S. J. Smith, Y.-W. Zheng et al., "Identification of a gene encoding an acyl CoA:diacylglycerol acyltransferase, a key enzyme in triacylglycerol synthesis," Proceedings of the National Academy of Sciences of the United States of America, vol. 95, no. 22, pp. 13018-13023, 1998.

[133] R. Coleman and R. M. Bell, "Triacylglycerol synthesis in isolated fat cells. Studies on the microsomal diacylglycerol acyltransferase activity using ethanol-dispersed diacylglycerols," The Journal of Biological Chemistry, vol. 251, no. 15, pp. 4537-4543, 1976.

[134] R. A. Coleman, T. M. Lewin, and D. M. Muoio, "Physiological and nutritional regulation of enzymes of triacylglycerol synthesis," Annual Review of Nutrition, vol. 20, pp. 77-103, 2000.

[135] R. Zechner, R. Zimmermann, T. O. Eichmann et al., "FAT SIGNALS-lipases and lipolysis in lipid metabolism and signaling," Cell Metabolism, vol. 15, no. 3, pp. 279-291, 2012.

[136] R. E. Gimeno and J. Cao, "Thematic review series: glycerolipids. Mammalian glycerol-3-phosphate acyltransferases: new genes for an old activity," The Journal of Lipid Research, vol. 49, no. 10, pp. 2079-2088, 2008.

[137] K. Takeuchi and K. Reue, "Biochemistry, physiology, and genetics of GPAT, AGPAT, and lipin enzymes in triglyceride synthesis," American Journal of Physiology-Endocrinology and Metabolism, vol. 296, no. 6, pp. E1195-E1209, 2009.

[138] A. A. Wendel, T. M. Lewin, and R. A. Coleman, "Glycerol-3phosphate acyltransferases: rate limiting enzymes of triacylglycerol biosynthesis," Biochimica et Biophysica Acta: Molecular and Cell Biology of Lipids, vol. 1791, no. 6, pp. 501-506, 2009. 
[139] L. S. Csaki and K. Reue, "Lipins: multifunctional lipid metabolism proteins," Annual Review of Nutrition, vol. 30, pp. 257272, 2010.

[140] R. Stienstra and S. Kersten, "Fight fat with DGAT," Journal of Lipid Research, vol. 52, no. 4, pp. 591-592, 2011

[141] E. Currie, A. Schulze, R. Zechner, T. C. Walther, and R. V. Farese Jr., "Cellular fatty acid metabolism and cancer," Cell Metabolism, vol. 18, no. 2, pp. 153-161, 2013.

[142] G. P. Holloway, L. A. Snook, R. J. Harris, J. F. C. Glatz, J. J. F. P. Luiken, and A. Bonen, "In obese Zucker rats, lipids accumulate in the heart despite normal mitochondrial content, morphology and long-chain fatty acid oxidation," The Journal of Physiology, vol. 589, no. 1, pp. 169-180, 2011.

[143] Z. K. Guo and M. D. Jensen, "Accelerated intramyocellular triglyceride synthesis in skeletal muscle of high-fat-induced obese rats," International Journal of Obesity, vol. 27, no. 9, pp. 10141019, 2003.

[144] X.-J. Zhang, D. L. Chinkes, Z. Wu, D. N. Herndon, and R. R. Wolfe, "The synthetic rate of muscle triglyceride but not phospholipid is increased in obese rabbits," Metabolism: Clinical and Experimental, vol. 58, no. 11, pp. 1649-1656, 2009.

[145] A. Bonen, M. L. Parolin, G. R. Steinberg et al., "Triacylglycerol accumulation in human obesity and type 2 diabetes is associated with increased rates of skeletal muscle fatty acid transport increased sarcolemmal FAT/CD36," FASEB Journal, vol. 18, no. 10, pp. 1144-1146, 2004.

[146] L. Vergnes, A. P. Beigneux, R. Davis, S. M. Watkins, S. G. Young, and K. Reue, "Agpat6 deficiency causes subdermal lipodystrophy and resistance to obesity," Journal of Lipid Research, vol. 47, no. 4, pp. 745-754, 2006.

[147] S. J. Smith, S. Cases, D. R. Jensen et al., "Obesity resistance and multiple mechanisms of triglyceride synthesis in mice lacking Dgat," Nature Genetics, vol. 25, no. 1, pp. 87-90, 2000.

[148] L. S. Csaki, J. R. Dwyer, X. Li et al., "Lipin-1 and lipin-3 together determine adiposity in vivo," Molecular Metabolism, vol. 3, no. 2, pp. 145-154, 2014.

[149] H. C. Chen and R. V. Farese Jr., "Inhibition of triglyceride synthesis as a treatment strategy for obesity: lessons from DGAT1-deficient mice," Arteriosclerosis, Thrombosis, and Vascular Biology, vol. 25, no. 3, pp. 482-486, 2005.

[150] L. E. Hammond, S. Neschen, A. J. Romanelli et al., "Mitochondrial glycerol-3-phosphate acyltransferase-1 is essential in liver for the metabolism of excess acyl-CoAs," The Journal of Biological Chemistry, vol. 280, no. 27, pp. 25629-25636, 2005.

[151] D. Lindén, L. William-Olsson, M. Rhedin, A.-K. Asztély, J. C. Clapham, and S. Schreyer, "Overexpression of mitochondrial GPAT in rat hepatocytes leads to decreased fatty acid oxidation and increased glycerolipid biosynthesis," The Journal of Lipid Research, vol. 45, no. 7, pp. 1279-1288, 2004.

[152] C. A. Nagle, L. Vergnes, H. Dejong et al., "Identification of a novel $s n$-glycerol-3-phosphate acyltransferase isoform, GPAT4, as the enzyme deficient in Agpat6 ${ }^{-/-}$mice," Journal of Lipid Research, vol. 49, no. 4, pp. 823-831, 2008.

[153] H. Ruan and H. J. Pownall, "Overexpression of 1-acyl-glycerol3-phosphate acyltransferase-alpha enhances lipid storage in cellular models of adipose tissue and skeletal muscle," Diabetes, vol. 50, no. 2, pp. 233-240, 2001.

[154] J. Phan and K. Reue, "Lipin, a lipodystrophy and obesity gene," Cell Metabolism, vol. 1, no. 1, pp. 73-83, 2005.

[155] C. Bagnato and R. A. Igal, "Overexpression of diacylglycerol acyltransferase-1 reduces phospholipid synthesis, proliferation, and invasiveness in simian virus 40-transformed human lung fibroblasts," The Journal of Biological Chemistry, vol. 278, no. 52, pp. 52203-52211, 2003.

[156] T. C. Walther and R. V. Farese, "Lipid droplets and cellular lipid metabolism," Annual Review of Biochemistry, vol. 81, pp. 687714, 2012.

[157] C. J. Antalis, T. Arnold, T. Rasool, B. Lee, K. K. Buhman, and R. A. Siddiqui, "High ACAT1 expression in estrogen receptor negative basal-like breast cancer cells is associated with LDLinduced proliferation," Breast Cancer Research and Treatment, vol. 122, no. 3, pp. 661-670, 2010.

[158] J. V. Swinnen, P. P. van Veldhoven, M. Esquenet, W. Heyns, and G. Verhoeven, "Androgens markedly stimulate the accumulation of neutral lipids in the human prostatic adenocarcinoma cell line LNCaP," Endocrinology, vol. 137, no. 10, pp. 4468-4474, 1996.

[159] N. G. Than, B. Sumegi, S. Bellyei et al., "Lipid droplet and milk lipid globule membrane associated placental protein $17 \mathrm{~b}$ (PP17b) is involved in apoptotic and differentiation processes of human epithelial cervical carcinoma cells," European Journal of Biochemistry, vol. 270, no. 6, pp. 1176-1188, 2003.

[160] A. M. Dvorak, P. F. Weller, V. S. Harvey, E. S. Morgan, and H. F. Dvorak, "Ultrastructural localization of prostaglandin endoperoxide synthase (cyclooxygenase) to isolated, purified fractions of guinea pig peritoneal macrophage and line 10 hepatocarcinoma cell lipid bodies," International Archives of Allergy and Immunology, vol. 101, no. 2, pp. 136-142, 1993.

[161] M. T. Accioly, P. Pacheco, C. M. Maya-Monteiro et al., "Lipid bodies are reservoirs of cyclooxygenase- 2 and sites of prostaglandin-E2 synthesis in colon cancer cells," Cancer Research, vol. 68, no. 6, pp. 1732-1740, 2008.

[162] E. Przybytkowski, É. Joly, C. J. Nolan et al., "Upregulation of cellular triacylglycerol-free fatty acid cycling by oleate is associated with long-term serum-free survival of human breast cancer cells," Biochemistry and Cell Biology, vol. 85, no. 3, pp. 301-310, 2007.

[163] R. J. DeBerardinis, J. J. Lum, G. Hatzivassiliou, and C. B. Thompson, "The biology of cancer: metabolic reprogramming fuels cell growth and proliferation," Cell Metabolism, vol. 7, no. 1, pp. 11-20, 2008.

[164] J. A. Villena, B. Viollet, F. Andreelli, A. Kahn, S. Vaulont, and H. S. Sul, "Induced adiposity and adipocyte hypertrophy in mice lacking the AMP-activated protein kinase-alpha2 subunit," Diabetes, vol. 53, no. 9, pp. 2242-2249, 2004.

[165] R. Zimmermann, J. G. Strauss, G. Haemmerle et al., "Fat mobilization in adipose tissue is promoted by adipose triglyceride lipase," Science, vol. 306, no. 5700, pp. 1383-1386, 2004.

[166] T. O. Eichmann, M. Kumari, J. T. Haas et al., "Studies on the substrate and stereo/regioselectivity of adipose triglyceride lipase, hormone-sensitive lipase, and diacylglycerol-Oacyltransferases," The Journal of Biological Chemistry, vol. 287, no. 49, pp. 41446-41457, 2012.

[167] G. Haemmerle, R. Zimmermann, M. Hayn et al., "Hormonesensitive lipase deficiency in mice causes diglyceride accumulation in adipose tissue, muscle, and testis," Journal of Biological Chemistry, vol. 277, no. 7, pp. 4806-4815, 2002.

[168] G. Fredrikson, P. Stralfors, N. O. Nilsson, and P. Belfrage, "Hormone-sensitive lipase of rat adipose tissue. Purification and some properties," The Journal of Biological Chemistry, vol. 256, no. 12, pp. 6311-6320, 1981.

[169] R. Zechner, P. C. Kienesberger, G. Haemmerle, R. Zimmermann, and A. Lass, "Adipose triglyceride lipase and the lipolytic 
catabolism of cellular fat stores," Journal of Lipid Research, vol. 50, no. 1, pp. 3-21, 2009.

[170] C. Gercel-Taylor, D. L. Doering, F. B. Kraemer, and D. D. Taylor, "Aberrations in normal systemic lipid metabolism in ovarian cancer patients," Gynecologic Oncology, vol. 60, no. 1, pp. 35-41, 1996.

[171] D. K. Nomura, J. Z. Long, S. Niessen, H. S. Hoover, S.-W. Ng, and B. F. Cravatt, "Monoacylglycerol lipase regulates a fatty acid network that promotes cancer pathogenesis," Cell, vol. 140, no. 1, pp. 49-61, 2010.

[172] H. de Naeyer, D. M. Ouwens, Y. van Nieuwenhove et al., "Combined gene and protein expression of hormone-sensitive lipase and adipose triglyceride lipase, mitochondrial content, and adipocyte size in subcutaneous and visceral adipose tissue of morbidly obese men," Obesity Facts, vol. 4, no. 5, pp. 407-416, 2011.

[173] D. Langin, A. Dicker, G. Tavernier et al., "Adipocyte lipases and defect of lipolysis in human obesity," Diabetes, vol. 54, no. 11, pp. 3190-3197, 2005.

[174] G. R. Steinberg, B. E. Kemp, and M. J. Watt, "Adipocyte triglyceride lipase expression in human obesity," American Journal of Physiology-Endocrinology and Metabolism, vol. 293, no. 4, pp. E958-E964, 2007.

[175] J. W. E. Jocken, D. Langin, E. Smit et al., "Adipose triglyceride lipase and hormone-sensitive lipase protein expression is decreased in the obese insulin-resistant state," The Journal of Clinical Endocrinology and Metabolism, vol. 92, no. 6, pp. 22922299, 2007.

[176] P. Oliver, A. Caimari, R. Díaz-Rúa, and A. Palou, "Dietinduced obesity affects expression of adiponutrin/PNPLA3 and adipose triglyceride lipase, two members of the same family," International Journal of Obesity, vol. 36, no. 2, pp. 225-232, 2012.

[177] R. A. Coleman and D. G. Mashek, "Mammalian triacylglycerol metabolism: synthesis, lipolysis, and signaling," Chemical Reviews, vol. 111, no. 10, pp. 6359-6386, 2011.

[178] Y. Liu, "Fatty acid oxidation is a dominant bioenergetic pathway in prostate cancer," Prostate Cancer and Prostatic Diseases, vol. 9, no. 3, pp. 230-234, 2006.

[179] J. Khasawneh, M. D. Schulz, A. Walch et al., "Inflammation and mitochondrial fatty acid $\beta$-oxidation link obesity to early tumor promotion," Proceedings of the National Academy of Sciences of the United States of America, vol. 106, no. 9, pp. 3354-3359, 2009.

[180] N. Turner, C. R. Bruce, S. M. Beale et al., "Excess lipid availability increases mitochondrial fatty acid oxidative capacity in muscle: evidence against a role for reduced fatty acid oxidation in lipid-induced insulin resistance in rodents," Diabetes, vol. 56, no. 8, pp. 2085-2092, 2007.

[181] G. P. Holloway, A. Bonen, and L. L. Spriet, "Regulation of skeletal muscle mitochondrial fatty acid metabolism in lean and obese individuals," American Journal of Clinical Nutrition, vol. 89, no. 1, pp. 455S-462S, 2009.

[182] M. W. Hulver, J. R. Berggren, R. N. Cortright et al., "Skeletal muscle lipid metabolism with obesity," The American Journal of Physiology-Endocrinology and Metabolism, vol. 284, no. 4, pp. E741-E747, 2003.

[183] J.-Y. Kim, R. C. Hickner, R. L. Cortright, G. L. Dohm, and J. A. Houmard, "Lipid oxidation is reduced in obese human skeletal muscle," American Journal of Physiology-Endocrinology and Metabolism, vol. 279, no. 5, pp. E1039-E1044, 2000.
[184] J. D. McGarry and N. F. Brown, "The mitochondrial carnitine palmitoyltransferase system. From concept to molecular analysis," European Journal of Biochemistry, vol. 244, no. 1, pp. 1-14, 1997.

[185] L. Abu-Elheiga, M. M. Matzuk, K. A. H. Abo-Hashema, and S. J. Wakil, "Continuous fatty acid oxidation and reduced fat storage in mice lacking acetyl-CoA carboxylase 2," Science, vol. 291, no. 5513, pp. 2613-2616, 2001.

[186] G. Peluso, R. Nicolai, E. Reda, P. Benatti, A. Barbarisi, and M. Calvani, "Cancer and anticancer therapy-induced modifications on metabolism mediated by carnitine system," Journal of Cellular Physiology, vol. 182, no. 3, pp. 339-350, 2000.

[187] N. T. Price, F. R. van der Leij, V. N. Jackson et al., "A novel brainexpressed protein related to carnitine palmitoyltransferase I," Genomics, vol. 80, no. 4, pp. 433-442, 2002.

[188] F. R. van der Leij, A. M. Kram, B. Bartelds et al., "Cytological evidence that the C-terminus of carnitine palmitoyltransferase I is on the cytosolic face of the mitochondrial outer membrane," Biochemical Journal, vol. 341, no. 3, pp. 777-784, 1999.

[189] P. Mazzarelli, S. Pucci, E. Bonanno, F. Sesti, M. Calvani, and L. G. Spagnoli, "Carnitine palmitoyltransferase I in human carcinomas: a novel role in histone deacetylation?" Cancer Biology and Therapy, vol. 6, no. 10, pp. 1606-1613, 2007.

[190] P. T. Reilly and T. W. Mak, "Molecular pathways: tumor cells Co-opt the brain-specific metabolism gene CPT1C to promote survival," Clinical Cancer Research, vol. 18, no. 21, pp. 5850-5855, 2012.

[191] A. Pacilli, M. Calienni, S. Margarucci et al., "Carnitine-acyltransferase system inhibition, cancer cell death, and prevention of myc-induced lymphomagenesis," Journal of the National Cancer Institute, vol. 105, no. 7, pp. 489-498, 2013.

[192] L. S. Pike, A. L. Smift, N. J. Croteau, D. A. Ferrick, and M. Wu, "Inhibition of fatty acid oxidation by etomoxir impairs NADPH production and increases reactive oxygen species resulting in ATP depletion and cell death in human glioblastoma cells," Biochimica et Biophysica Acta, vol. 1807, no. 6, pp. 726-734, 2011.

[193] I. Samudio, R. Harmancey, M. Fiegl et al., "Pharmacologic inhibition of fatty acid oxidation sensitizes human leukemia cells to apoptosis induction," The Journal of Clinical Investigation, vol. 120, no. 1, pp. 142-156, 2010.

[194] S. J. Wakil, E. B. Titchener, and D. M. Gibson, "Evidence for the participation of biotin in the enzymic synthesis of fatty acids," Biochimica et Biophysica Acta, vol. 29, no. 1, pp. 225-226, 1958.

[195] L. Abu-Elheiga, W. Oh, P. Kordari, and S. J. Wakil, "AcetylCoA carboxylase 2 mutant mice are protected against obesity and diabetes induced by high-fat/high-carbohydrate diets," Proceedings of the National Academy of Sciences of the United States of America, vol. 100, no. 18, pp. 10207-10212, 2003.

[196] A. J. Iverson, A. Bianchi, A.-C. Nordlund, and L. A. Witters, "Immunological analysis of acetyl-CoA carboxylase mass, tissue distribution and subunit composition," Biochemical Journal, vol. 269, no. 2, pp. 365-371, 1990.

[197] K. G. Thampy, "Formation of malonyl coenzyme A in rat heart. Identification and purification of an isozyme of acetyl coenzyme A carboxylase from rat heart," The Journal of Biological Chemistry, vol. 264, no. 30, pp. 17631-17634, 1989.

[198] K. G. Thampy and S. J. Wakil, "Regulation of acetyl-coenzyme A carboxylase. I. Purification and properties of two forms of acetyl-coenzyme A carboxylase from rat liver," The Journal of Biological Chemistry, vol. 263, no. 13, pp. 6447-6453, 1988. 
[199] H. J. Harwood Jr., "Treating the meytabolic syndrome: acetylCoA carboxylase inhibition," Expert Opinion on Therapeutic Targets, vol. 9, no. 2, pp. 267-281, 2005.

[200] L. Tong, "Structure and function of biotin-dependent carboxylases," Cellular and Molecular Life Sciences, vol. 70, no. 5, pp. 863-891, 2013.

[201] C. Wang, C. Xu, M. Sun, D. Luo, D.-F. Liao, and D. Cao, "Acetyl-CoA carboxylase-alpha inhibitor TOFA induces human cancer cell apoptosis," Biochemical and Biophysical Research Communications, vol. 385, no. 3, pp. 302-306, 2009.

[202] A. Beckers, S. Organe, L. Timmermans et al., "Chemical inhibition of acetyl-CoA carboxylase induces growth arrest and cytotoxicity selectively in cancer cells," Cancer Research, vol. 67, no. 17, pp. 8180-8187, 2007.

[203] V. Chajès, M. Cambot, K. Moreau, G. M. Lenoir, and V. Joulin, "Acetyl-CoA carboxylase $\alpha$ is essential to breast cancer cell survival," Cancer Research, vol. 66, no. 10, pp. 5287-5294, 2006.

[204] K. Brusselmans, E. de Schrijver, G. Verhoeven, and J. V. Swinnen, "RNA interference-mediated silencing of the acetyl-Coacarboxylase- $\alpha$ gene induces growth inhibition and apoptosis of prostate cancer cells," Cancer Research, vol. 65, no. 15, pp. 67196725, 2005.

[205] S.-M. Jeon, N. S. Chandel, and N. Hay, "AMPK regulates $\mathrm{NADPH}$ homeostasis to promote tumour cell survival during energy stress," Nature, vol. 485, no. 7400, pp. 661-665, 2012.

[206] W. Zhou, Y. Tu, P. J. Simpson, and F. P. Kuhajda, "MalonylCoA decarboxylase inhibition is selectively cytotoxic to human breast cancer cells," Oncogene, vol. 28, no. 33, pp. 2979-2987, 2009.

[207] G. K. Bandyopadhyay, J. G. Yu, J. Ofrecio, and J. M. Olefsky, "Increased malonyl-CoA levels in muscle from obese and type 2 diabetic subjects lead to decreased fatty acid oxidation and increased lipogenesis; thiazolidinedione treatment reverses these defects," Diabetes, vol. 55, no. 8, pp. 2277-2285, 2006.

[208] G. R. Steinberg, B. J. Michell, B. J. W. van Denderen et al., "Tumor necrosis factor $\alpha$-induced skeletal muscle insulin resistance involves suppression of AMP-kinase signaling," Cell Metabolism, vol. 4, no. 6, pp. 465-474, 2006.

[209] M. Yamasaki, S. Hasegawa, T. Kitani, K. Hidai, and T. Fukui, "Differential effects of obesity on acetoacetyl-CoA synthetase gene in rat adipose tissues," European Journal of Lipid Science and Technology, vol. 109, no. 6, pp. 617-622, 2007.

[210] A. Janovská, G. Hatzinikolas, V. Staikopoulos, J. McInerney, M. Mano, and G. A. Wittert, "AMPK and ACC phosphorylation: effect of leptin, muscle fibre type and obesity," Molecular and Cellular Endocrinology, vol. 284, no. 1-2, pp. 1-10, 2008.

[211] K. L. Mullen, J. Pritchard, I. Ritchie et al., "Adiponectin resistance precedes the accumulation of skeletal muscle lipids and insulin resistance in high-fat-fed rats," American Journal of Physiology: Regulatory Integrative and Comparative Physiology, vol. 296, no. 2, pp. R243-R251, 2009.

[212] J. M. Peterson, S. Aja, Z. Wei, and G. W. Wong, "CTRP1 protein enhances fatty acid oxidation via AMP-activated protein kinase (AMPK) activation and acetyl-CoA carboxylase (ACC) inhibition," Journal of Biological Chemistry, vol. 287, no. 2, pp. 15761587, 2012.

[213] M. D. Fullerton, S. Galic, K. Marcinko et al., "Single phosphorylation sites in Accl and Acc2 regulate lipid homeostasis and the insulin-sensitizing effects of metformin," Nature Medicine, vol. 19, no. 12, pp. 1649-1654, 2013. 


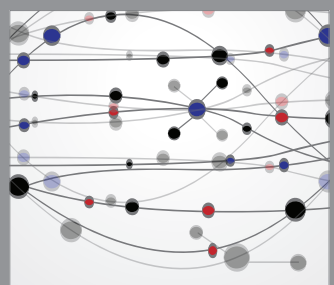

The Scientific World Journal
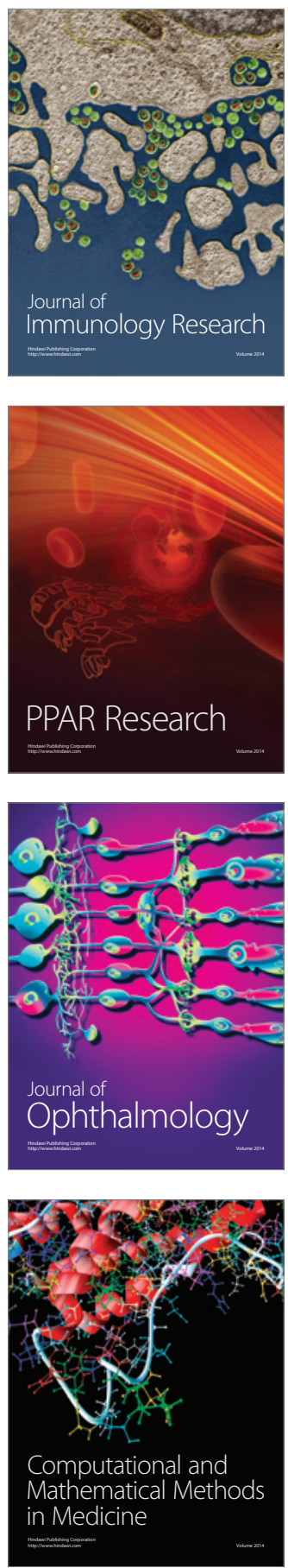

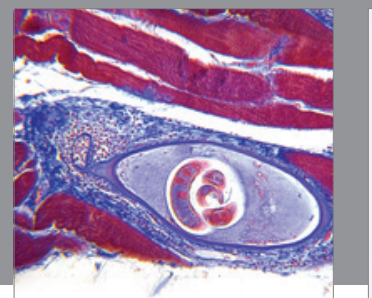

Gastroenterology

Research and Practice
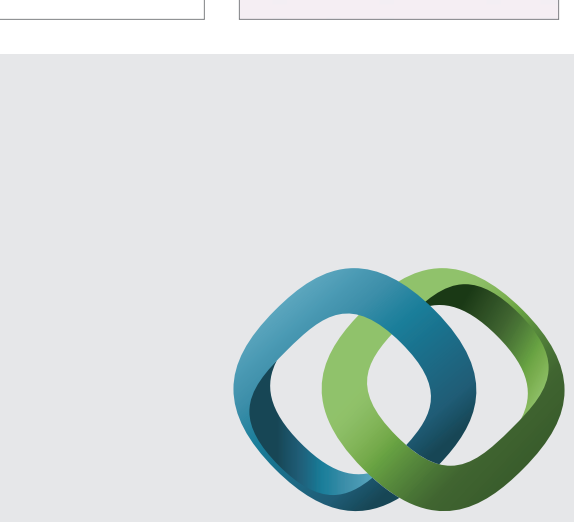

\section{Hindawi}

Submit your manuscripts at

http://www.hindawi.com
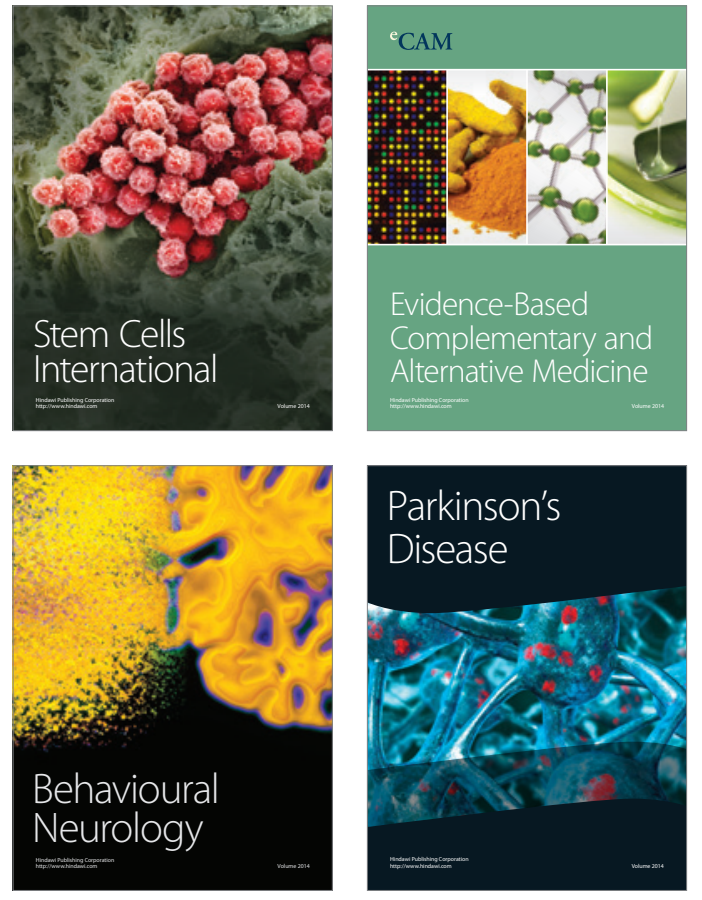
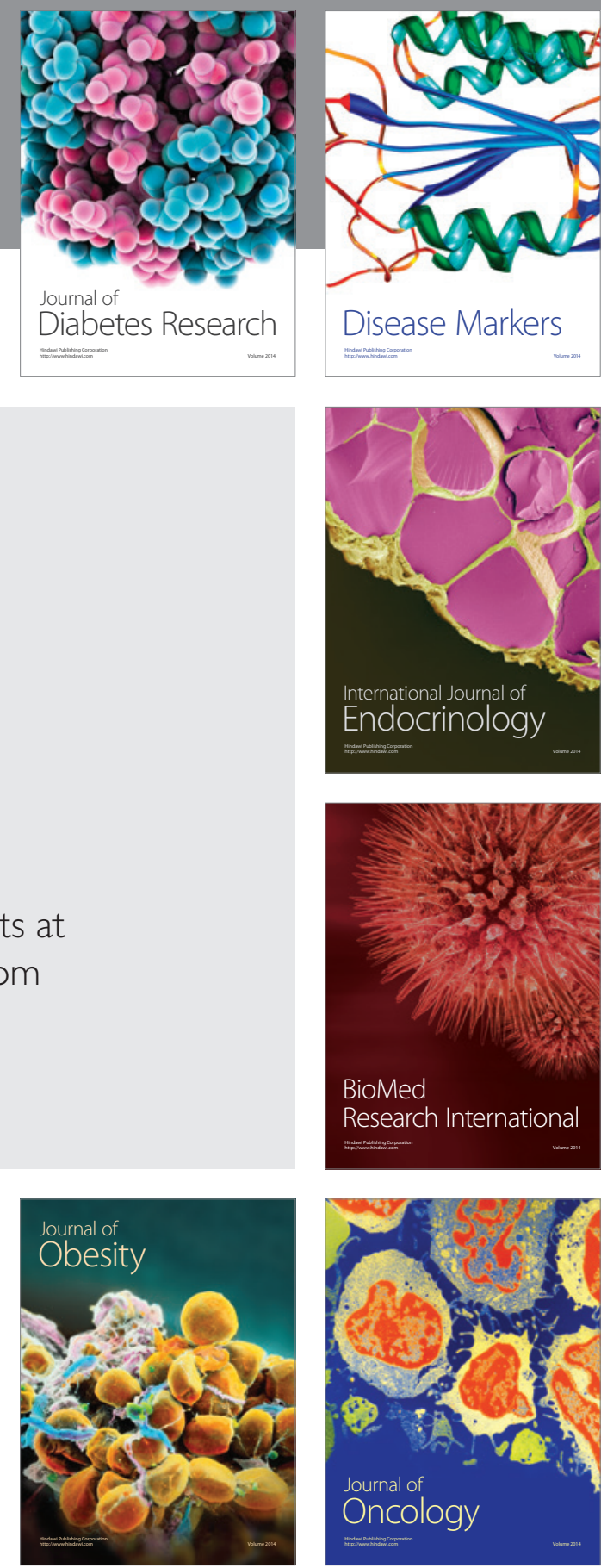

Disease Markers
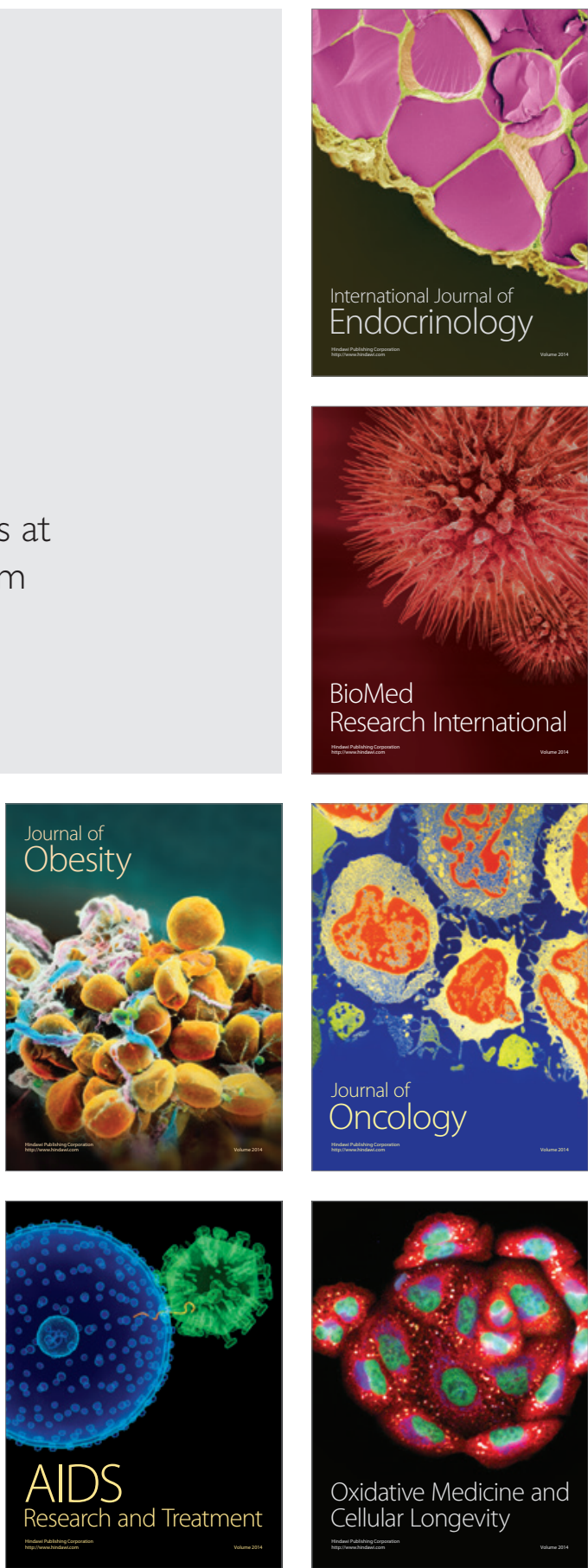